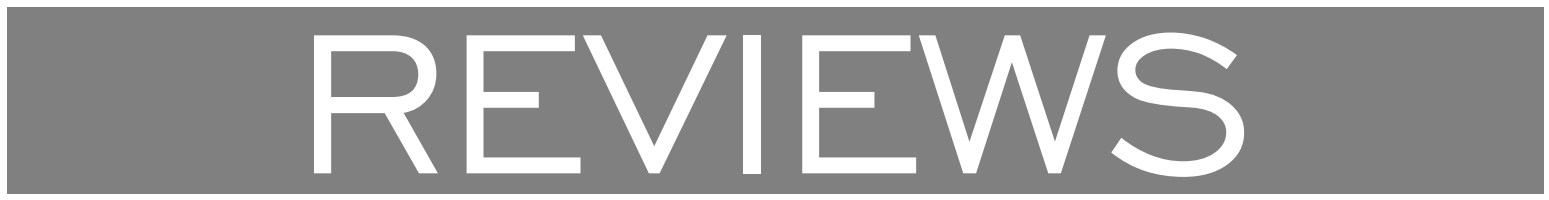

Ecological Monographs, 85(1), 2015, pp. 29-47

(C) 2015 by the Ecological Society of America

\title{
Keystone species: toward an operational concept for marine biodiversity conservation
}

\author{
Audrey Valls, ${ }^{1,5}$ Marta Coll,${ }^{2,3,4}$ and Villy Christensen ${ }^{1}$ \\ ${ }^{1}$ Fisheries Centre, University of British Columbia, 2202 Main Mall, Vancouver, British Columbia V6T $1 Z 4$ Canada \\ ${ }^{2}$ Institut de Ciències del Mar (ICM-CSIC), Passeig Maritim de la Barceloneta 37-49, 08003 Barcelona, Spain \\ ${ }^{3}$ Institut de Recherche pour le Développement, UMR EME 212, Centre de Recherche Halieutique Méditerranéenne et Tropicale, \\ Avenue Jean Monnet, BP 171, 34203 Sète, France \\ ${ }^{4}$ Ecopath International Initiative Research Association, Barcelona, Spain
}

\begin{abstract}
Various definitions and indices have been proposed in the literature to identify keystone species. In this study, we intended to make the concept of keystone species operational for marine biodiversity conservation. We used an exclusive definition of keystone species, based on the original concept of keystone predator, and derived a new functional index of keystoneness (KS) from an ecosystem-modeling approach. First, several KS indices were formulated, by combining measures of the mixed-trophic impact (MTI) and biomass of species. Then, a meta-analysis was performed, based on 101 published Ecopath food-web models, selected with a scoring method, and representative of the variety of marine ecosystems worldwide. The indices were applied to the models, and two statistical methods were compared to select the most promising KS index. Rank correlation tests were performed to assess the balance between the contribution of the impact and biomass components to the different KS indices. In addition, a classification tree was implemented, based on ecosystemspecific thresholds applied to the latter species traits, and used to confirm the identified keystone species. The selected index obtained the highest number of models with positive results from both the rank correlation tests and the classification tree. We also demonstrated the limitations of existing KS indices previously applied in the literature. Species were ranked according to their estimates of keystoneness with the selected KS index, so that potential keystone species were quantitatively identified in the 101 modeled food webs. The standardized modeling approach allowed for a comparison of the identified keystone species across models: cartilaginous fishes and toothed whales obtained the highest occurrences. Finally, the selected KS index was applied to the well-known case study of Prince William Sound (Alaska, USA). Potentially significant anthropogenic (fishing) impacts on keystone species were also considered and discussed. The operational methodology presented is directly applicable to marine food webs, and may be adapted to other (freshwater or terrestrial) systems.
\end{abstract}

Key words: classification tree; Ecopath model; food-web structure; index of keystoneness; keystone species; marine ecosystems; meta-analysis; mixed-trophic impact; rank correlation tests; scoring method.

\section{INTRODUCTION}

The metaphorical terminology of keystone species was introduced in aquatic food-web ecology by R. T. Paine (1969). A keystone species was first described as a predator maintaining high species diversity and complex interspecific feeding relationships in the community

Manuscript received 12 February 2014; revised 6 August 2014; accepted 12 August 2014. Corresponding Editor: A. M. Ellison.

${ }^{5}$ E-mail: a.valls@fisheries.ubc.ca
(Paine 1966). Variations in the keystone species abundance or activity would have greater impacts on biodiversity and trophic structure, compared to other coexisting species with similar or higher abundance in the ecosystem (Paine 1969). Since Paine's analogy, the concept of keystone species has rapidly expanded, as it has been applied to an ever-growing number of aquatic and terrestrial species, playing a wide variety of critical roles in the ecosystem (Paine 1995, Power and Mills 1995, Power et al. 1996). Many authors discussed the relevance of the keystone species term (Hurlbert 1997), 
which has been turned into an inclusive concept, either described as a powerful buzzword in conservation (Barua 2011), or criticized as an ambiguous and overused concept (Cottee-Jones and Whittaker 2012). As pointed out by Paine (1995), "an answer serving all masters probably provides few useful solutions." Thus, in this study, a clear, exclusive, and thus operational, definition of keystone species was applied, based on the original concept of keystone predator (Paine 1966, 1969). More precisely, we defined a keystone species as a predator species which disproportionately influences the food-web structure of its community. In other words, we considered a keystone species to correspond to a predator species with a high and wide impact on its food web, despite a low biomass.

Experts reviewed the methods used to identify keystone species and concluded that the most powerful approach was the combination of comparative studies with experimental methods (Power et al. 1996), as conducted by several authors (e.g., Paine 1966, Menge et al. 1994). However, field experiments have practical limitations. Field-based experimental removals of a single species are expensive and time-consuming, restricted in scope (both spatially and temporally), and may be challenging with some types of species (either not easily accessible, or under some restrictive protection statuses; Power et al. 1996, Bond 2001, Libralato et al. 2006). Thus, experimental approaches often require focusing on a few species only, a priori assumed to be the potential keystones, which may introduces bias in the analysis of keystoneness (Libralato et al. 2006). To overcome these difficulties, recent approaches to identify potential keystone species were based on a variety of ecological modeling methods: ecological network analysis (ENA; Jordán et al. 1999, 2007, 2009, Estrada 2007, Torres-Alruiz and Rodríguez 2013); loop analysis (e.g., Ortiz et al. 2013a, b); community viability analysis (e.g., Christianou and Ebenman 2005, Ebenman and Jonsson 2005, Berg et al. 2011, Stouffer et al. 2012); or food-web models (e.g., Okey et al. 2004, Libralato et al. 2006, Eddy et al. 2014).

Different indices measuring the potential of species to be critical to the community were proposed and reviewed in the literature (Jordán et al. 2008, Jordán 2009, Perry 2010, Cottee-Jones and Whittaker 2012). Initially, the proposed indices were based either on observations from the field (e.g., interaction strength [Paine 1992] or community importance [Mills et al. 1993, Power et al. 1996]), or on theoretical concepts (e.g., general functional importance [Hurlbert 1997] or functional group dominance [Davic 2003]). A suite of structural indices, derived from binary or weighted networks, was then developed: degree (Jordán et al. 2003, Scotti et al. 2007), centrality indices (Estrada 2007), overlap indices (Jordán 2009), topological importance of species (Jordán et al. 2008), and trophic function and trophic field overlap (Jordán et al. 2009). Recently, a topo-dynamical criterion, which estimates the consequences of species removal on community dynamics, was proposed in the ENA literature (TorresAlruiz and Rodríguez 2013). Additionally, qualitative indices, based on loop analysis models, were introduced and compared to existing structural and functional indices (Ortiz et al. 2013a,b). Three indices explicitly quantifying species keystoneness were proposed: a structural index $(K)$ based on network analysis (Jordán et al. 1999), a dynamic index (KI) based on timedynamic simulations (Okey et al. 2004), and a functional index (KS) based on mass-balanced modeling (Libralato et al. 2006).

In this study, we used the Ecopath with Ecosim (EwE) modeling approach to estimate species keystoneness and identify potential keystone species in marine communities. EwE is a well-known and widely applied modeling approach in aquatic ecology (Coll et al. 2008, Christensen et al. 2011). The EwE software is freely available online. ${ }^{6}$ Published EwE models have become more and more accessible, such that the approach has been applied to hundreds of aquatic ecosystems worldwide, and several meta-analyses, based on EwE models, have already been published (Colléter et al. 2013). EwE-based studies help with understanding the general structure and functioning of aquatic ecosystems, by summarizing the available knowledge on a given ecosystem, deriving its various system properties, and comparing them to other ecosystems (Walters et al. 1997). The EwE modeling approach was primarily developed to answer "what if" questions about policy that could not be addressed with single-species assessment models (Christensen and Walters 2004). Thus, EwE is more suitable to studying aquatic food webs than terrestrial ones and has been primarily applied to marine ecosystems. In this study, we only considered EwE models representing marine ecosystems.

EwE may be described as an ecosystem model since it represents feeding relationships between all species occurring in the ecosystem, although it only captures trophic interactions, not nutrient cycling. EwE is based on Ecopath, a food-web model first proposed and applied to estimate the main predator-prey pathways in the marine ecosystem of the northwestern Hawaiian Islands (Polovina 1984). The original Ecopath model was then developed further (Christensen and Pauly 1992), and turned into the EwE modeling complex, which can be seen as a toolbox offering a large collection of methods to analyze various ecological phenomena. The EwE modeling complex consists of a suite of three main sub-models: (1) Ecopath, static and descriptive, (2) Ecosim, dynamic and predictive, and (3) Ecospace, spatially explicit, dynamic, and predictive (Christensen and Walters 2004). Ecopath is a descriptive model, representing a static snapshot of the ecosystem trophic structure, and used as a parameter estimation methodology in the EwE modeling complex (Walters et al.

\footnotetext{
${ }^{6}$ www.ecopath.org
} 
1997). Ecosim uses the outputs of Ecopath to produce time-dynamic simulations of changing trophic interactions with changes in the ecosystem due to anthropogenic or environmental disturbances (Walters et al. 1997). Ecosim may be used to fit model predictions to time-series data, and to explore different fisheries management or climate change scenarios (Christensen and Walters 2004). Ecospace replicates outputs of Ecosim over a spatial grid to explicitly account for the spatial aspects of trophic structure, and was primarily designed for exploring the possible consequences of alternative marine protected areas policies (Walters et al. 1999).

In this study, we focused on three main questions related to the identification of keystone species in marine ecosystems: (1) What are the limitations of the existing functional indices measuring species keystoneness? (2) Could these limitations explain the inconsistencies and discrepancies observed when applying these indices to modeled food webs? (3) How could we formulate a new functional index overcoming these limitations? We intended to answer these questions based on a metaanalysis of published Ecopath models representing marine food webs. First, models were selected with a scoring method. Second, several indices of keystoneness were formulated, comprising new and existing indices. Third, the indices were applied to the models, and the obtained keystone species were recorded. A preliminary comparison of the results was made to identify potential biases in the indices. Then, two statistical methods were used to select the most suitable index: Spearman rank correlation tests and a classification tree. The new functional index of keystoneness was selected according to the indicated definition of keystone species and applied to a well-known case study.

\section{Methods}

Derivation of indices of keystoneness from Ecopath foodweb models

Selection of the Ecopath models with a scoring method.-The data used in this study were extracted from 101 Ecopath food-web models. First, the EcoBase database was used to establish the list of models to select from. EcoBase is an online repository, referencing and integrating information from more than 400 published EwE models (Colléter et al. 2013). We extracted critical metadata on the models stored in EcoBase, and reused some of the metadata as selection criteria in our analysis. Then, the data extracted from the selected models were accessed through another collection of EwE models (Christensen et al. 2011).

We collected a suite of metadata from EcoBase, including the ecosystem type, the climatic zone, the first and last year, the spatial extent, and the reference of the models. We excluded from our analysis all referenced models representing non-marine ecosystem types. Among the marine types, models were selected by applying a scoring method, based on six criteria: (1) an analysis of keystoneness (KS) was previously performed with this model, (2) the model represented an established Marine Protected Area (MPA); (3) one (or more) historical version(s), or "sibling," of the same modeled ecosystem was available; (4) the model was focusing on a species (or group of species) of particular interest; (5) detailed information on species aggregation into functional groups was available for this model; and (6) another (or more) geographical version(s), called "overlapping," of the same modeled ecosystem was available. We note that criteria 1,2 , and 3 were particularly relevant to our study, whereas criteria 4,5 , and 6 were less significant. Outcomes from past analyses of keystone species on the same ecosystems could be compared to our results. Models representing MPAs, or successive historical versions of the same area, could be used to understand fishing impact on marine food webs and keystone species. In contrast, species of particular interest might or might not be keystone species, and information on species aggregation might or might not help identifying keystone species. Overlapping models were very few in the EcoBase database.

All criteria correspond to metadata directly extracted from EcoBase, apart from criteria 3 and 6, which were refined for the purpose of this study. Sibling models (criteria 3) were more precisely defined here as models with the same geographic location and surface area, but representing different years or time periods. Overlapping models (criteria 6) were defined as models with the same geographic location and time period, but not necessarily the same surface area (i.e., representing the ecosystem at smaller or larger spatial scales). Each criterion was given a score of 1 if true and 0 if false. For each model, the final score was obtained by summing the scores of the six criteria, with a coefficient of 2 applied to the first three criteria, since they were more relevant to this study. The final scores ranged from 0 to 6 . Models were selected only if their final score was equal to or higher than 3 . Nonetheless, models with an overall score lower than 3 , but a positive score for one of the first three criteria (of higher importance), were also considered.

Description of the Ecopath modeling approach.Ecopath describes the feeding relationships between all species occurring in the modeled food web. Species are aggregated into functional (or trophic) groups, corresponding to an age/size class of a single species, a single species, or a group of species sharing similar ecological traits (such as size, diet, predator, and life cycle; Christensen et al. 2008). A functional group can also be defined as a group of species with similar effects on ecosystem processes, without redundancy among the other groups (Perry 2010). Thus, a keystone species may be represented by a functional group (De Leo and Levin 1997, Perry 2010), or by the most abundant species within its functional group (Davic 2003). As a result, the terminologies keystone groups and keystone species are used interchangeably in this study. 
The main assumption in Ecopath is of mass balance over a given time period (typically one year; Christensen and Walters 2004). For each functional group, Ecopath assumes that the energy input and output are balanced in the ecosystem, and that the system has the same biomass state at the end of the period as it had at the beginning (Walters et al. 1997). The mass-balance constraint serves as a filter for mutually incompatible estimates in the model. All available data collected about the components of the ecosystem pass through the mass balance filter, which determines what the parameters must be to support the current trophic structure and be consistent with observations (Walters et al. 1997, Christensen and Walters 2004). See Appendix A for details on the Ecopath model and Appendix B for an illustrative example.

For each selected Ecopath model, we gathered, from the collection of EwE models (Christensen et al. 2011), the name and the biomass $\left(B, \mathrm{Mg} / \mathrm{km}^{2}\right)$ of each living group (dead groups, such as detritus, were excluded), and deduced the total number of living groups in the model and their total biomass in the ecosystem ( $B_{\text {tot }}$, $\mathrm{Mg} / \mathrm{km}^{2}$ ). Biomass is usually entered as input data in Ecopath, but may be estimated by the model if missing. As a first data quality check, we recorded the number of biomass estimates computed by Ecopath for each model $\left(B_{\text {estim }}\right)$, and deduced the proportion of estimated biomass. Although we did not use Ecosim in our analysis, we recorded for each selected model if the Ecopath model was fitted to time series in Ecosim or not (metadata extracted from EcoBase), and used it as a second data quality check. A supplementary parameter, the trophic level (TL, dimensionless), was collected for each living group in each selected model. TL is a fractional number giving the position of each functional group in its food web (generally ranging from 1 to 5), and estimated by Ecopath based on the diet composition of the group and the TL of its prey items (starting with a TL of 1 assigned to producers and detritus; Christensen and Pauly 1992). Some of the selected models described ecosystems exploited by one or more fishing fleets. For these models, we collected the total number of fishing fleets in the model and the total catch rate ( $Y_{\text {tot }}$, $\left.\mathrm{Mg} \cdot \mathrm{km}^{-2} \cdot \mathrm{yr}^{-1}\right)$ of all fishing fleets in the ecosystem. The mean trophic level of the catch $\left(\mathrm{TL}_{Y}\right.$, dimensionless), estimated by Ecopath based on the composition of the total catch and the TL of the targeted groups (Christensen et al. 2008), was collected as well.

Description of the mixed-trophic impact (MTI) analysis and derived $K S$ indices.-Several modules were developed and added to the EwE package, such as the network analysis module, a tool available with the Ecopath model (Christensen et al. 2008). The network analysis notably comprises the mixed-trophic impact (MTI) and keystoneness (KS) analyses. The MTI is an economic input-output analysis adapted to ecological networks by Ulanowicz and Puccia (1990), and implemented in Ecopath (Christensen and Walters 2004). The
MTI is calculated by constructing an $n \times n$ matrix, whose elements $\left(m_{i j}\right)$ represent, for each pair of groups $(i, j)$ in the modeled food web, the relative impact of the impacting group $i$ on the impacted group $j$, by considering direct (predation) and indirect (competition) feeding interactions (Ulanowicz and Puccia 1990, Christensen and Walters 2004). The $m_{i j}$ are also estimated for each fishing fleet defined in the model, by considering fishing fleets as predators (Christensen and Walters 2004). See Appendix A for details on the MTI analysis and Appendix B for an illustrative example.

Two alternative indices measuring the potential for being a keystone species, or keystoneness (KS), were implemented in the KS analysis of the network analysis module in EwE (Christensen et al. 2008). The first index (called $\mathrm{KS}_{1}$ in EwE) was proposed by Libralato et al. (2006), and the second one (called $\mathrm{KS}_{2}$ in EwE) was adapted from a methodology proposed by Power et al. (1996). Both indices are estimated based on the same parameters: a measure of trophic impact $\left(\varepsilon_{i}\right)$ derived from the MTI analysis, and a measure of biomass $\left(p_{i}\right)$. Parameter $\varepsilon_{i}$ represents the overall effect of group $i$ on all the other groups in the food web (without including the effect of the group on itself)

$$
\varepsilon_{i}=\sqrt{\sum_{j \neq i} m_{i j}^{2}}
$$

where $\varepsilon_{i}$ is expressed as the sum of the squared values of $m_{i j}$ of group $i$, paired with each of the other living group $j$ in the food web. The mixed-trophic impact of group $i$ on itself $\left(m_{i i}\right)$ is excluded, as well as the mixed-trophic impact on dead groups such as detritus (Libralato et al. 2006).

Parameter $p_{i}$ corresponds to the contribution of group $i$ to the total biomass in the food web

$$
p_{i}=\frac{B_{i}}{\sum_{k=1}^{n} B_{k}}
$$

where $B_{i}$ is the biomass of group $i$, and $B_{k}$ the biomass of each of the $n$ living groups in the food web (Power et al. 1996, Libralato et al. 2006).

The $\mathrm{KS}_{1}$ and $\mathrm{KS}_{2}$ indices are obtained by combining $\varepsilon_{i}$ and $p_{i}$ for each group $i$ (Power et al. 1996, Libralato et al. 2006), such as

$$
\begin{aligned}
\mathrm{KS}_{1 i} & =\log \left[\varepsilon_{i} \times\left(1-p_{i}\right)\right] \\
\mathrm{KS}_{2 i} & =\log \left[\varepsilon_{i} \times\left(1 / p_{i}\right)\right] .
\end{aligned}
$$

Formulation and application of several KS indices.-In both the $\mathrm{KS}_{1}$ and $\mathrm{KS}_{2}$ indices, the $\mathrm{KS}$ is estimated based on two components: (1) a component estimating the trophic impact of the group (here called impact component; IC), and (2) a component estimating the 
biomass of the group (here called biomass component; $\mathrm{BC})$, so that a general equation for an index of KS may be expressed

$$
\mathrm{KS}_{i}=\log \left[\mathrm{IC}_{i} \times \mathrm{BC}_{i}\right] .
$$

Based on the general equation of KS (Eq. 5), we explored several formulations and combinations of IC and $\mathrm{BC}$. We retained three different ICs and four different BCs, and combined the seven components in all possible ways to obtain 12 alternative KS indices (Table 1). ICs were calculated using a measure of trophic impact $\left(\varepsilon_{i} ; \mathrm{Eq} .1\right)$, and BCs using a measure of biomass $\left(p_{i}\right.$; Eq. $\left.2, B_{i}\right)$. To avoid imbalance between both components, BCs and ICs were defined so that they had value ranges of comparable orders of magnitude. One of the ICs and two of the BCs were directly adapted from the literature (Power et al. 1996, Libralato et al. 2006) and denoted with subscripted letters $\left(\mathrm{IC}_{\mathrm{L}}, \mathrm{BC}_{\mathrm{L}}\right.$, $\mathrm{BC}_{\mathrm{P}}$ ), while the other components were marked with subscripted numbers, with a zero for the components using ranks $\left(\mathrm{IC}_{0}\right.$ and $\left.\mathrm{BC}_{0}\right) . \mathrm{KS}_{1}$ and $\mathrm{KS}_{2}$ were directly adopted from the literature and correspond to the indices described in Eqs. 3 and 4.

The 12 retained KS indices were applied to the 101 selected modeled ecosystems. The names of the groups with the highest value of keystoneness were recorded for each KS index and each model. The $m_{i j}$ values were extracted from Ecopath for each living functional group (dead groups such as detritus were not considered) of each selected model, and $\varepsilon_{i}$ was calculated as described in Eq. 1. As described in Eq. 2, $p_{i}$ was derived from the $B_{i}$ values extracted from Ecopath. Contrary to previous approaches (e.g., Libralato et al. 2006), the $m_{i j}$ corresponding to fishing fleets were included in our analysis. We assumed that fishing fleets could be added as a supplementary functional group, if considered as a predator feeding on targeted groups. Therefore, a supplementary group, called "all fleets" was added as an $n+1$ functional group, in all selected models representing exploited ecosystems. All defined fishing fleets were combined together into the all-fleets group, whose $B_{i}$ and $\mathrm{TL}_{i}$ were approximated with $Y_{\text {tot }}$ and $\mathrm{TL}_{Y}$, respectively. For models with multiple fleets, $m_{i j}$ of all fleets was obtained by summing up the $m_{i j}$ values over all the defined fishing fleets.

\section{Analysis of the contributions of the IC and BC components to the keystoneness estimation}

Comparison of groups ordered by keystoneness, trophic impact, and biomass. - To test the $12 \mathrm{KS}$ indices (Table 1), we analyzed the balance between IC and BC components for each index. First, we compared, for each KS index and each selected model, the groups ordered by keystoneness, with the groups ordered by trophic impact and biomass, separately. Precisely, we compared the group of the highest keystoneness with: (1) the three groups with the highest values of trophic impact $\left(\varepsilon_{i}\right)$ and (2) the three groups with the lowest
TABLE 1. Equations of the 12 indices of keystoneness (KS), obtained by combining each impact component (IC) with each biomass component (BC).

\begin{tabular}{cl}
\hline \hline Impact components and $\mathrm{KS}$ indices & Biomass components \\
\hline $\mathrm{IC}_{\mathrm{L}}=\varepsilon_{i}$ & \\
$\mathrm{KS}_{1}=\mathrm{IC}_{\mathrm{L}} \times \mathrm{BC}_{\mathrm{L}}$ & $\mathrm{BC}_{\mathrm{L}}=1-p_{i}$ \\
$\mathrm{KS}_{2}=\mathrm{IC}_{\mathrm{L}} \times \mathrm{BC}_{\mathrm{P}}$ & $\mathrm{BC}_{\mathrm{P}}=1 / p_{i}$ \\
$\mathrm{KS}_{3}=\mathrm{IC}_{\mathrm{L}} \times \mathrm{BC}_{0}$ & $\mathrm{BC}_{0}=\operatorname{drank}\left(B_{i}\right)$ \\
$\mathrm{KS}_{4}=\mathrm{IC}_{\mathrm{L}} \times \mathrm{BC}_{1}$ & $\mathrm{BC}_{1}=1 / \sqrt{B_{i}}$ \\
$\mathrm{IC}_{0}=\operatorname{arank}\left(\varepsilon_{i}\right)$ & \\
$\mathrm{KS}_{5}=\mathrm{IC}_{0} \times \mathrm{BC}_{\mathrm{L}}$ & $\mathrm{BC}_{\mathrm{L}}=1-p_{i}$ \\
$\mathrm{KS}_{6}=\mathrm{IC}_{0} \times \mathrm{BC}_{\mathrm{P}}$ & $\mathrm{BC}_{\mathrm{P}}=1 / p_{i}$ \\
$\mathrm{KS}_{7}=\mathrm{IC}_{0} \times \mathrm{BC}_{0}$ & $\mathrm{BC}_{0}=$ drank $\left(B_{i}\right)$ \\
$\mathrm{KS}_{8}=\mathrm{IC}_{0} \times \mathrm{BC}_{1}$ & $\mathrm{BC}_{1}=1 / \sqrt{B_{i}}$ \\
$\mathrm{IC}_{1}=\varepsilon_{i}^{2}$ & \\
$\mathrm{KS}_{9}=\mathrm{IC}_{1} \times \mathrm{BC}_{\mathrm{L}}$ & $\mathrm{BC}_{\mathrm{L}}=1-p_{i}$ \\
$\mathrm{KS}_{10}=\mathrm{IC}_{1} \times \mathrm{BC}_{\mathrm{P}}$ & $\mathrm{BC}_{\mathrm{P}}=1 / p_{i}$ \\
$\mathrm{KS}_{11}=\mathrm{IC}_{1} \times \mathrm{BC}_{0}$ & $\mathrm{BC}_{0}=\mathrm{drank}\left(B_{i}\right)$ \\
$\mathrm{KS}_{12}=\mathrm{IC}_{1} \times \mathrm{BC}_{1}$ & $\mathrm{BC}_{1}=1 / \sqrt{B_{i}}$ \\
\hline
\end{tabular}

Notes: ICs were calculated using a measure of trophic impact $\left(\varepsilon_{i}\right.$; Eq. 1$)$, and BCs using a measure of biomass ( $p_{i}$; Eq. $\left.2, B_{i}\right)$. The components adapted from the literature were subscripted as follows: $\mathrm{IC}_{\mathrm{L}}$ and $\mathrm{BC}_{\mathrm{L}}$ (Libralato et al. 2006), and $\mathrm{BC}_{\mathrm{P}}$ (Power et al. 1996). The other components were marked with subscripted numbers, with a zero for the components using ranks: $\mathrm{IC}_{0}$ and $\mathrm{BC}_{0}$. The abbreviations arank and drank designate the rank of the variable, with a ranking in ascending and descending order, respectively.

values of biomass $\left(B_{i}\right)$. If the group with the highest keystoneness value also had one of the three highest trophic impact values, then the model was categorized as "match impact" for the particular index. In contrast, if the group with the highest keystoneness value also had one of the three lowest biomass values, then the model was categorized as "match biomass" for the particular index. If the group with the highest keystoneness did not correspond to any of the three groups, neither with the highest trophic impact, nor with the lowest biomass, then the model was categorized as "no match" for the particular index. The methodology was applied to each of the 101 selected models, and the number of models in each matching category (match biomass, match impact, or no match) was recorded, for each KS index. The "overall match," obtained for each KS index over all models, corresponded to the matching category of the majority of models (i.e., 51 models or more, for a total of 101 models).

Rank correlation tests between KS indices and trophic impact or biomass estimates.-To analyze further the balance between IC and $\mathrm{BC}$ components for each $\mathrm{KS}$ index, we applied the Spearman's rank correlation test (Coleman 2010) using the R software (R Development Core Team 2014). We tested if there was a monotonic correlation between the rank (in ascending order, because keystone species should have high keystoneness) of the KS index of group $i$, called $\operatorname{arank}\left(\mathrm{KS}_{i}\right)$, and: (1) the rank (in ascending order, because keystone species should have high trophic impact) of the trophic impact of group $i$, called $\operatorname{arank}\left(\varepsilon_{i}^{2}\right)$ and (2) the rank (in descending order, 
since keystone species should have low biomass) of the biomass of group $i$, called $\operatorname{drank}\left(B_{i}\right)$. The Spearman's rank correlation test was applied twice (once with the trophic impact, and once with the biomass) to each KS index. The rank correlation tests were validated for each model, if and only if, for the particular KS index: (1) the hypothesis $H_{1}$ (i.e., there is a monotonic correlation) of the Spearman's rank correlation test was validated for both tests 1 and 2; (2) the coefficient of correlation $r$ was positive for both tests 1 and 2; and (3) the correlation coefficients $r_{1}$ and $r_{2}$ of tests 1 and 2 were of the same order of magnitude (a constraint was applied to the value of $r_{2}$ so that $r_{2}=r_{1} \pm 0.2 ; 0.2$ is a limit on the difference between $r_{1}$ and $r_{2}$ ). The methodology was applied to each of the 101 selected models, and we recorded, for each KS index, the number of models with validated rank correlation tests (i.e., satisfying the three conditions specified). We also ran, for comparison, the same tests without applying any constraint on the order of magnitude of the correlation coefficients.

\section{Selection of the most promising KS index}

Implementation of a classification tree.-We implemented a classification tree (Fig. 1a), as an alternative to the KS indices for the identification of keystone species among the functional groups of each modeled ecosystem. The classification was based on two log-transformed parameters: the trophic impact (in squared values; $\left.\varepsilon_{i}^{2}\right)$ and biomass $\left(B_{i}\right)$ of each group $i$. Four main categories were discriminated: keystone (corresponding to groups with high impact and low biomass), lowimpact-low-biomass, low-impact-high-biomass, highimpact-high-biomass, and intermediate (corresponding to groups belonging to none of the previous categories). Quartiles values of both $\varepsilon_{i}^{2}$ and $B_{i}$ parameters, over all living groups in each model, were set as thresholds to identify groups belonging to each category. The third quartiles $\left(Q_{3}\right)$ were set as lower thresholds for delimiting groups with high $\varepsilon_{i}^{2}$ and $B_{i}$, with the first quartiles $\left(Q_{1}\right)$ as upper thresholds for groups with low $\varepsilon_{i}^{2}$ and $B_{i}$. The other thresholds were defined by the minimum or maximum values of $\varepsilon_{i}^{2}$ and $B_{i}$ recorded for each modeled ecosystem. Then, among the identified keystone species, we separated the ones with a high trophic level from the others. Thus, a supplementary parameter, the trophic level $\left(\mathrm{TL}_{i}\right)$ of each group, was used to discriminate the keystone groups in two subcategories: low TL keystone (whose TL was lower than the third quartile values of TL), and high TL keystone (whose TL was equal to or higher than $Q_{3 \mathrm{TL}}$ ). The classification tree was applied to each of the 101 selected models, and a scatterplot representing the classification of each group was produced for each model (Fig. 1b). The categories identified with the classification tree were recorded for all groups and all models.

Comparison between keystone groups identified with the $K S$ indices and with the classification tree.-The keystone groups identified with the classification tree were compared to the ones identified with the KS indices. Precisely, for each of the 101 selected models and each of the KS indices, we compared the group with the highest value of keystoness with the KS index to the groups categorized as (low or high TL) keystone with the classification tree. If the group with the highest KS index value was classified in the (low or high TL) keystone categories of the classification tree, then the identified keystone group was considered validated, for the selected model. The methodology was applied to each of the 101 selected models, and we recorded, for each KS index, the number of models with validated keystone group.

In addition, once the most promising $\mathrm{KS}$ index was selected (see next paragraph), the groups identified as keystone (i.e., with the highest value of keystoneness) with the selected index were compared across the 101 selected models. Then, we compared the most frequently identified groups with the selected index and with the classification tree. Since the 101 models followed different rules for naming their respective functional groups, the names of the identified keystone groups with the selected index were standardized before comparison. Groups were renamed (and sometimes aggregated) using generic group names, based on their original designations. The same standardization method was applied to the groups classified as low or high TL keystone with the classification tree.

Allocation of overall statuses to the KS indices.-The conclusions from the rank correlation tests and the classification tree were summarized and compared by allocating different statuses to each Ecopath-model-KSindex pair (Fig. 2). The results obtained from the status allocation were used for the selection of the most promising of the $12 \mathrm{KS}$ indices applied in the analysis. Statuses were allocated according to predefined rules and following three steps: (1) if the $\mathrm{KS}$ index was validated (correlated positively with IC and $\mathrm{BC}$, and with correlation coefficients of the same order of magnitude), then the result from the rank correlation tests was positive, negative if not; (2) if the identified keystone group was validated (group of highest keystoneness with the KS index classified in the keystone categories of the classification tree), then the result from the classification tree was positive, negative if not; (3) if results from both steps 1 and 2 were positive (alternately negative), then the status was labeled as "true positive," (alternately "true negative"), but if step 1 was positive and step 2 negative (alternately step 1 negative and step 2 positive), then the status was labeled as "false positive" (alternately "false negative"). Thus, there were four alternative statuses possible for each Ecopath-modelKS-index pair: true positive, false positive, false negative, and true negative. In other words, when the result from the rank correlation tests (step 1) was positive, the status was labeled as positive, negative if not, and when the result from the classification tree (step 2) was in agreement with step 1, the status was also 


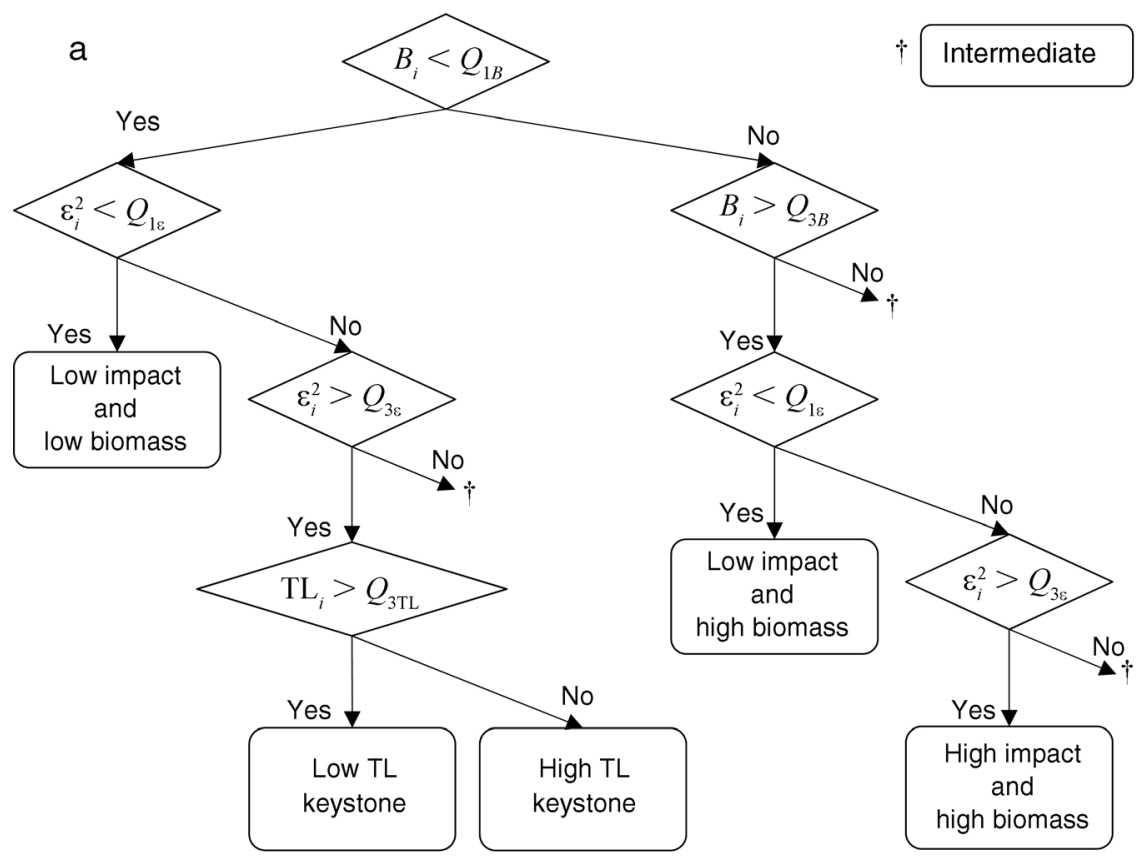

b

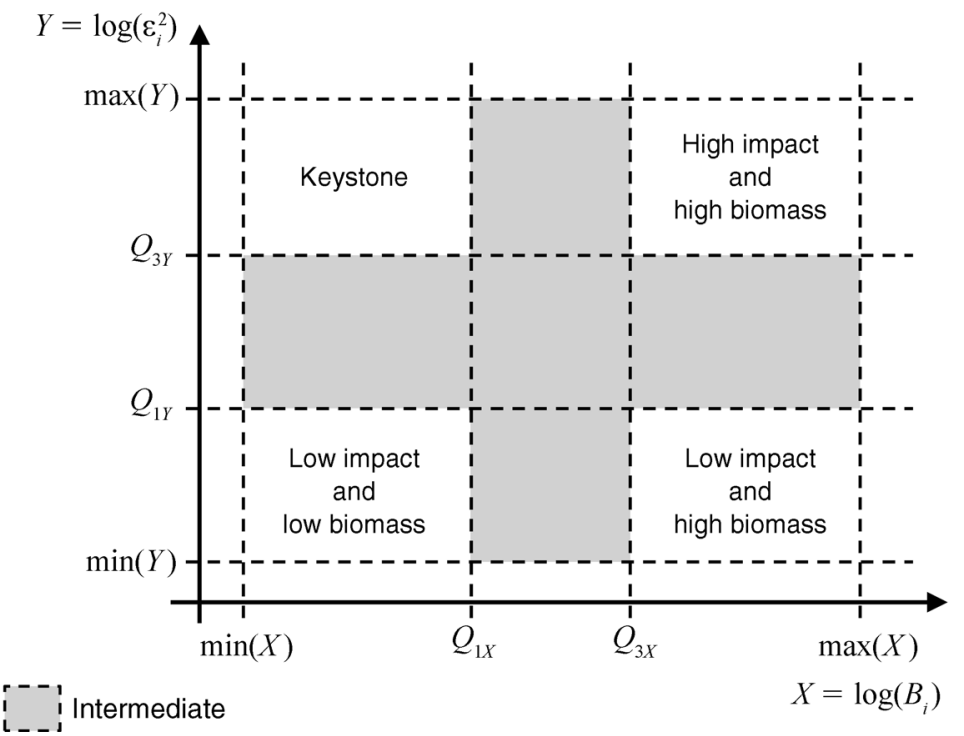

FIG. 1. Identification of keystone species with a classification tree. (a) Classification tree for the identification of keystone species among the functional groups of each modeled ecosystem. The classification is based on two (log-transformed) parameters: the group $i$ to the total biomass $\left(B_{i}\right)$ and trophic impact (in squared values; $\varepsilon_{i}^{2}$ ) of each group $i$. Groups are classified using the first quartile $\left(Q_{1}\right)$ and third quartile $\left(Q_{3}\right)$ values of the parameters over all living groups in each model, as lower and upper thresholds; $Q_{1}$ indicates first quartile biomass values, $Q_{1 \varepsilon}$ indicates first quartile trophic impact values, etc. Four main categories are discriminated: keystone (i.e., groups with high impact and low biomass), low-impact-low-biomass, low-impact-high-biomass, highimpact-high-biomass, and intermediate. The keystone category is subdivided into two sub-categories: low TL keystone and high TL keystone, by comparing the trophic level $\left(\mathrm{TL}_{i}\right)$ of the group to the third-quartile values of TL $\left(Q_{3 \mathrm{TL}}\right)$. The diamond-shaped boxes represent yes/no questions, and the rectangle-shaped boxes the categories identified after answering the questions. (b) Simplified graphical representation of the classification tree on a scatterplot, with the log-transformed biomass $\left(B_{i}\right)$ on the $x$-axis, and the log-transformed trophic impact (in squared values; $\varepsilon_{j}^{2}$ ) on the $y$-axis. The upper-left box represents the area where the (low TL and high TL) keystone groups are located, the upper-right box where the high-impact-high-biomass groups are, the lower-left box where the low-impact-low-biomass groups are, and the lower-right box where low-impact-high-biomass groups are. Each category box is defined based on the classification tree, using the minimum (min), maximum (max), $Q_{1}$, and $Q_{3}$ values (see Fig. 1a). Intermediate groups are spread on the rest of the plotting area (shaded in gray).

$\dagger$ Daggers represent the intermediate category. 


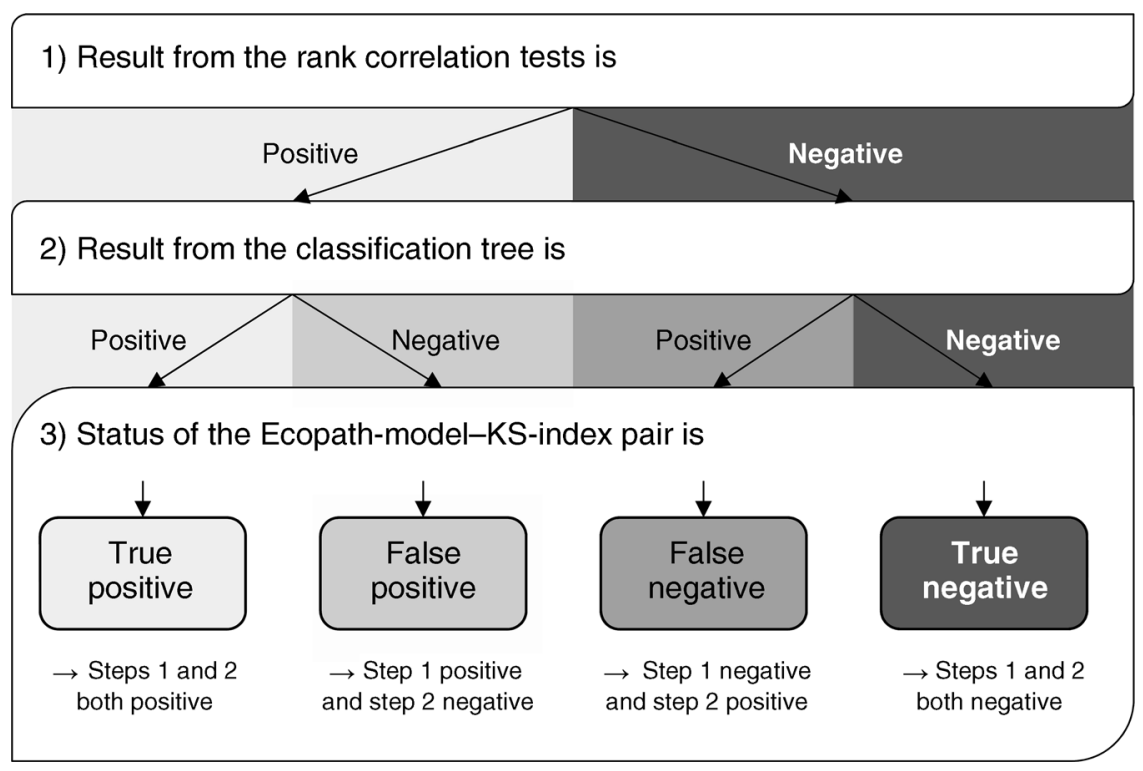

FIG. 2. Rules for status allocation to each Ecopath-model-KS-index pair. The statuses were allocated in three steps: (1) if the KS index was validated, then the result from the rank correlation tests was positive, negative if not; (2) if the identified keystone group was validated, then the result from the classification tree was positive, negative if not; (3) if results from steps 1 and 2 were both positive (respectively both negative), then the status was labeled as "true positive," (respectively "true negative"), but if step 1 was positive and step 2 negative (respectively step 1 negative and step 2 positive), then the status was labeled as "false positive" (respectively "false negative"). Four alternative statuses are possible for each Ecopath-model-KS-index pair: true positive, false positive, false negative, and true negative. A positive result for step 1 means that the KS index was validated for the selected model, because it was correlated positively with the impact component (IC) and biomass component (BC), with correlation coefficients of the same order of magnitude (Table 1). A positive result for step 2 means that the identified keystone group was validated for the selected model, since the group of the highest keystoneness with the KS index was categorized as keystone with the classification tree.

labeled as true, false if not. For some models, none of the functional groups were classified in the keystone categories of the classification tree, so that the identified keystone group could not be confirmed (step 2). Thus, a supplementary status was defined for these models, and labeled as "no keystone." The status allocation was performed for each of the 101 selected models, and the number of models associated with each status (true positive, false positive, false negative, true negative, and no keystone) was recorded for each KS index. The "overall status," obtained for each KS index over all models, corresponded to the status allocated to the majority of models.

\section{Application to a case study}

A case study was chosen to which both the classification tree and the selected KS index were applied. We chose the Ecopath model representing Prince William Sound, a nearly enclosed embayment located in the northern Gulf of Alaska, USA for the time period between 1994 and 1996, and covering an area of about $9000 \mathrm{~km}^{2}$, with a mean depth of $300 \mathrm{~m}$ (Okey and Pauly 1999). This Ecopath model was originally built to better understand the structure and functioning of the food web, based on the information provided by a panel of 35 experts (Okey and Pauly
1999). See Appendix B for graphical representations of the Prince William Sound (1994-1996) food web.

\section{Results}

\section{Pool of selected Ecopath models}

After applying the scoring method, we obtained a selection of 101 Ecopath models, whose final scores ranged from 2 to 6 . Analyses of keystone species were previously performed on 23 of the 101 models. In fact, most models were included in the meta-analysis introducing the $\mathrm{KS}_{2}$ index (Libralato et al. 2006), or had the latter index applied by their authors, while four models had alternative original methods proposed by the modelers applied (Aydin et al. 2002, Kitchell et al. 2002, Okey et al. 2004). The selection comprises 13 models representing MPAs, and only five of them are fully unexploited ecosystems (no fishing fleet defined). However, the no keystone status was allocated to the majority of the MPA models. About one-third (39) of the selected models focus on a (group of) species of particular interest. The selection includes 81 sibling models, but only two overlapping models. In fact, only 48 of the sibling models are suitable for comparative analyses, since some models did not have their corresponding siblings selected, others had different species aggregations between siblings, and some siblings 
were associated with the no keystone status. See Appendix $\mathrm{C}$ : Table $\mathrm{C} 1$ for the detailed results of the scoring method for each selected model.

Most of the 101 selected models seem to be goodquality models in terms of data. A large proportion of the models (78) provide detailed information on species aggregation into functional groups. Approximately onethird of the selected models do not have any biomass input data computed by Ecopath, and the proportion of estimated biomass is lower than $25 \%$ for the second onethird, and lower than $75 \%$ for the last one-third (up to $95 \%$ for only one model). Besides, the selection comprises 43 Ecopath models fitted to time series. See Appendix C: Tables $\mathrm{C} 2$ and $\mathrm{C} 3$ for the detailed metadata and references of each of the 101 models.

The 101 selected models represent a wide variety of marine ecosystems. Continental shelf (less than $200 \mathrm{~m}$ deep) is the most represented type of ecosystem, with 41 models. Six other types are represented in smaller proportions: ocean (more than $200 \mathrm{~m}$ deep, 19 models), upwelling (16 models), channel or strait (10 models), bay or fjord (seven models), coral reef (seven models), and coastal lagoon (one model). Most modeled ecosystems are located in temperate or tropical zones (58 and 36 models, respectively), and few in polar zones (seven models). About two-thirds of the selected models represent ecosystems over a time period of one year, and the last one-third covers time periods lasting from two to 11 years (up to 40 years for one model). About half of the models describe ecosystems in the recent past (49 models for the 1990s-2000s), while the other half describe ecosystems in less recent times $(26$ models for the 1970s-1980s, 18 models for the 1950s-1960s, and eight models for periods before 1950). The spatial extent of the selected models varies from 2.48 to more than $18000000 \mathrm{~km}^{2}$, but most models cover an area smaller than $500000 \mathrm{~km}^{2}$ (Fig. 3a). Among the selected models, ecosystems of the ocean and continental shelf types have wider ranges of spatial extent, whereas the ocean and upwelling types cover the largest areas, followed by continental shelf and channel or strait (Fig. 3a). Coral reef ecosystems have the widest range and highest values of total biomass (Fig. 3b), whereas upwelling ecosystems have the widest range of total catch, followed by bay or fjord and channel or strait (Fig. 3c). The number of living groups in the 101 selected models ranges from six to 96 , with most models comprising 20 to 40 groups (Fig. 4a). The number of fishing fleets varies from zero to 19 , with 14 models without fleet, and most models including 1-5 fleets (Fig. 4b). Among models with defined fishing fleets, the mean trophic level of the catch ranges from 1.02 to 4.52 , and is between 3 and 3.5 for most models (Fig. 4c).

\section{Balance in the contributions of IC and BC to the $\mathrm{KS}$ indices}

The comparison between the groups ordered by keystoneness and by trophic impact and biomass,
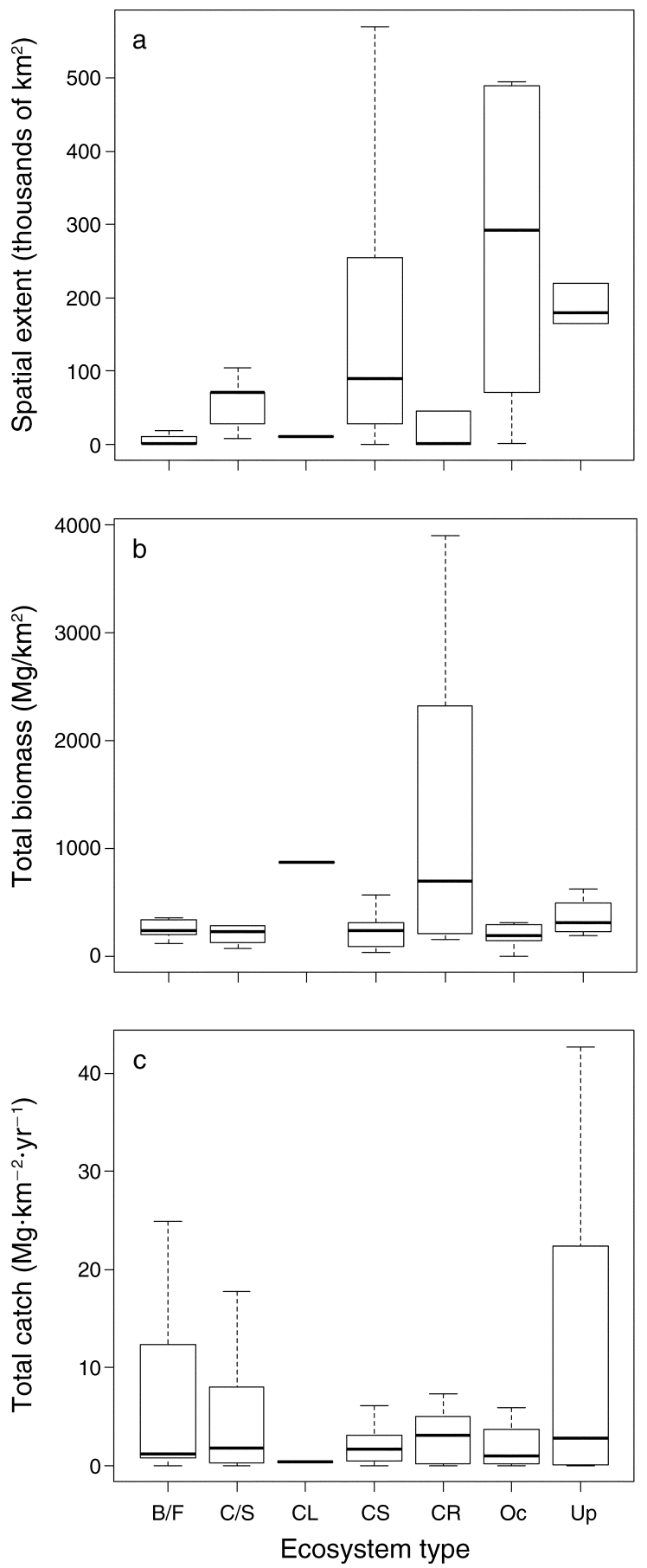

FIG. 3. Boxplots of (a) spatial extent (area), (b) total biomass $\left(B_{\text {tot }}\right)$, and (c) total catch $\left(Y_{\text {tot }}\right)$, for all selected Ecopath models, categorized by type of modeled ecosystem: bay/fjord $(\mathrm{B} / \mathrm{F})$, channel/strait $(\mathrm{C} / \mathrm{S})$, coastal lagoon $(\mathrm{CL})$, continental shelf (CS), coral reef (CR), ocean (Oc), or upwelling (Up). The line in the box represents the median or second quartile. The limits of the box represent the first and third quartiles. Whiskers represent the lowest and highest data points which are no more than 1.5 times the interquartile range of the lower and upper quartiles from the box. 

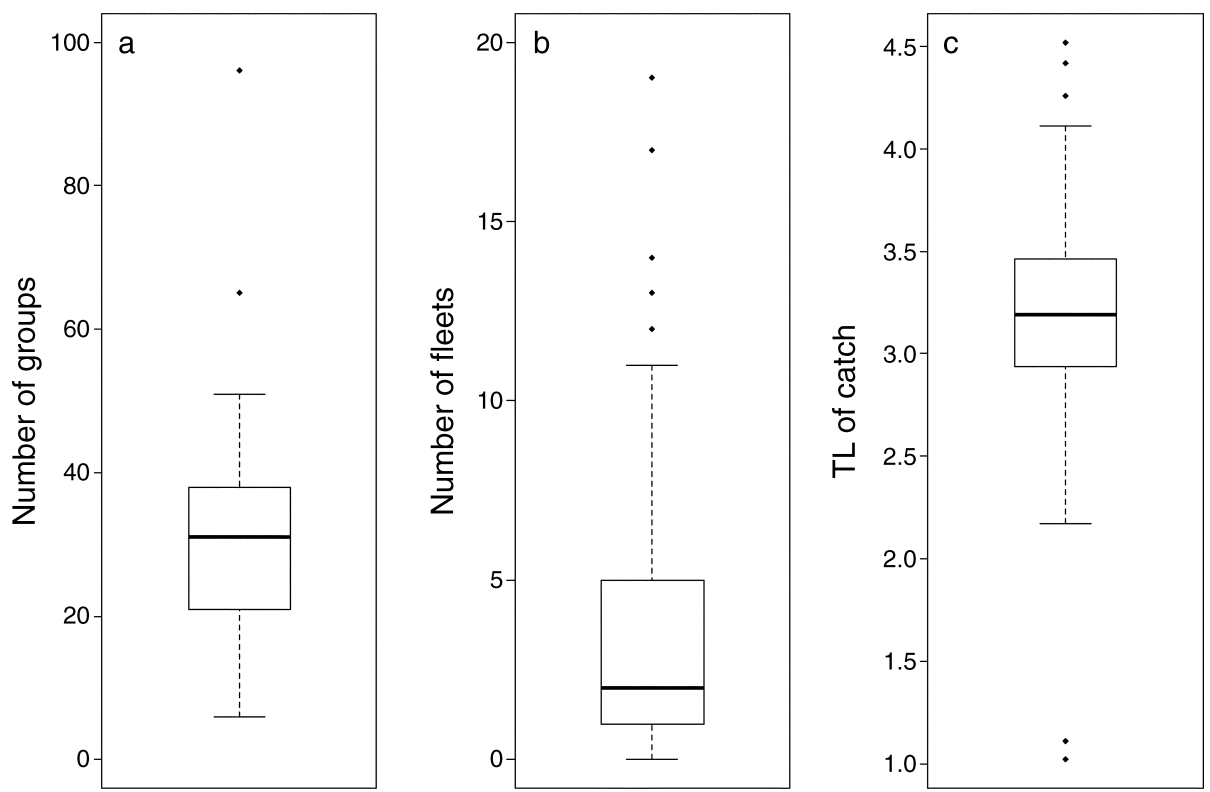

FIG. 4. Boxplots showing (a) number of living groups, (b) number of fishing fleets, and (c) mean trophic level of the catch $\left(\mathrm{TL}_{Y}\right)$, for all selected Ecopath models. The line in the box represents the median or second quartile. The limits of the box represent the first and third quartiles. Whiskers represent the lowest and highest data points which are no more than 1.5 times the interquartile range of the lower and upper quartiles from the box. The dots represent the outliers or extreme data points.

applied to the 101 Ecopath models and for each KS index, shows that three of the KS indices out of the 12 seem to be balanced: $\mathrm{KS}_{3}, \mathrm{KS}_{7}$, and $\mathrm{KS}_{12}$ (Table 2). For these three indices, the spreading of the models is comparable between the three matching categories, so that not one of the categories is associated with the majority of models (51 or more) and no overall match is determined. Thus, for these three indices, the group with the highest keystoneness value may also have one of the three highest trophic impact values, or one of the three lowest biomass values, or none of the previous, with similar probabilities. Nonetheless, we note that the number of models is higher (and close to the majority) in the match impact category for the $\mathrm{KS}_{3}$ index. In addition, the comparison shows that both $\mathrm{KS}_{1}$ and $\mathrm{KS}_{2}$ indices (directly adapted from the literature) are unbalanced. $\mathrm{KS}_{1}$ has a significantly higher number of models (91) in the match impact category, meaning that this index tends to identify keystone groups mainly based on their (high) trophic impact. In contrast, $\mathrm{KS}_{2}$ has a significantly higher number of models (81) in the match biomass category, so that it would identify keystone groups primarily based on their (low) biomass. The overall match of the other KS indices corresponds to either match impact or match biomass, determined with a more or less substantial majority of models.

The rank correlation tests are validated for a majority of the 101 models for only one of the $12 \mathrm{KS}$ indices: $\mathrm{KS}_{3}$, with 75 models with validated tests (Table 3 ). Both the $\mathrm{KS}_{1}$ and $\mathrm{KS}_{2}$ indices show significantly lower numbers of models with validated rank correlation tests, with 40
TABLE 2. Results from the comparison between groups ordered by keystoneness, and by trophic impact or biomass, for each KS index, over all selected models.

\begin{tabular}{lcccl}
\hline \hline $\begin{array}{c}\text { KS } \\
\text { index }\end{array}$ & $\begin{array}{c}\text { Match } \\
\text { impact }\end{array}$ & $\begin{array}{c}\text { Match } \\
\text { biomass }\end{array}$ & $\begin{array}{c}\text { No } \\
\text { match }\end{array}$ & $\begin{array}{c}\text { Overall } \\
\text { match }\end{array}$ \\
\hline $\mathrm{KS}_{1}$ & 91 & 10 & 0 & match impact \\
$\mathrm{KS}_{2}$ & 5 & 81 & 15 & match biomass \\
$\mathrm{KS}_{3}$ & 50 & 28 & 23 & \\
$\mathrm{KS}_{4}$ & 25 & 54 & 22 & match biomass \\
$\mathrm{KS}_{5}$ & 86 & 12 & 3 & match impact \\
$\mathrm{KS}_{6}$ & 0 & 94 & 7 & match biomass \\
$\mathrm{KS}_{7}$ & 32 & 35 & 34 & \\
$\mathrm{KS}_{8}$ & 11 & 70 & 20 & match biomass \\
$\mathrm{KS}_{9}$ & 91 & 10 & 0 & match impact \\
$\mathrm{KS}_{10}$ & 25 & 54 & 22 & match biomass \\
$\mathrm{KS}_{11}$ & 71 & 20 & 10 & match impact \\
$\mathrm{KS}_{12}$ & 46 & 39 & 16 & \\
\hline
\end{tabular}

Notes: Indices $\mathrm{KS}_{1}$ and $\mathrm{KS}_{2}$ are adapted from the literature, and $\mathrm{KS}_{3}$ is the selected index. The number of models whose group with the highest keystoneness matched one of the three groups with highest trophic impact $\left(\varepsilon_{i}\right)$ is shown in the match impact column, the number whose group with the highest keystoneness matched one of the three groups with the lowest biomass $\left(B_{i}\right)$, is shown in the match biomass column. The number of models for which the group with the highest keystoneness value matched none of the three groups with, either the highest trophic impact, or the lowest biomass, is shown in the no match column. In the overall match column, results are expressed as an overall match for each KS index over all models, corresponding to the matching category of the majority of models (i.e., 51 models or more, for a total of 101 models) for the particular index. Cells left blank indicate no majority. See Table 1 for detailed equations of each KS index. 
TABLE 3. Results from the rank correlation tests (Correlation), the classification tree (Keystone category; see Fig. 1) and the status allocation (true positive, false positive, false negative, true negative, overall status; see Fig. 2), for each KS index.

\begin{tabular}{|c|c|c|c|c|c|c|c|}
\hline KS index & Correlation & Keystone category & True positive & False positive & False negative & True negative & $\overline{\text { Overall status }}$ \\
\hline $\mathrm{KS}_{1}$ & $40(95)$ & 15 & 7 & 21 & 8 & 32 & \\
\hline $\mathrm{KS}_{2}$ & $12(52)$ & 34 & 6 & 5 & 32 & 25 & \\
\hline $\mathrm{KS}_{3}$ & 75 (99) & 48 & 40 & 12 & 14 & 2 & true positive \\
\hline $\mathrm{KS}_{4}$ & $0(0)$ & 50 & 0 & 0 & 55 & 13 & false negative \\
\hline $\mathrm{KS}_{5}$ & $0(0)$ & 22 & 0 & 0 & 22 & 46 & true negative \\
\hline $\mathrm{KS}_{6}$ & $44(50)$ & 22 & 17 & 24 & 9 & 18 & \\
\hline $\mathrm{KS}_{7}$ & $9(14)$ & 59 & 7 & 1 & 59 & 1 & false negative \\
\hline $\mathrm{KS}_{8}$ & $0(51)$ & 43 & 0 & 0 & 48 & 20 & false negative \\
\hline $\mathrm{KS}_{9}$ & $0(8)$ & 15 & 0 & 0 & 15 & 53 & true negative \\
\hline $\mathrm{KS}_{10}$ & $1(1)$ & 50 & 0 & 1 & 55 & 12 & false negative \\
\hline $\mathrm{KS}_{11}$ & $2(8)$ & 35 & 1 & 0 & 37 & 30 & false negative \\
\hline $\mathrm{KS}_{12}$ & $3(7)$ & 47 & 2 & 1 & 51 & 14 & false negative \\
\hline
\end{tabular}

Notes: Values correspond to the number of models with validated rank correlation tests (correlation), whose identified keystone group with KS index is categorized as keystone with classification tree (keystone category), and whose associated status correspond to each of the possible statuses (true positive, false positive, false negative, and true negative). Values given in the correlation column are for results with a constraint applied on the correlation coefficients, the results with no constraint applied are shown in parentheses. In the overall status column, results are expressed as an overall status for each KS index, corresponding to the status of the majority of models (i.e., 35 models or more, since 33 models over the 101 models in total were allocated a no keystone status), for the particular index. Cells left blank indicate no majority. See Table 1 for detailed equations of each KS index.

and 12 models, respectively. The other KS indices have less than 10 models with validated tests (apart from $\mathrm{KS}_{6}$, with 44 models). Thus, the results from the tests demonstrate a better balance between IC and BC components for the $\mathrm{KS}_{3}$ index, for which high keystoneness values seem to correlate, with the same order of magnitude, to high trophic impact and low biomass values. When the constraint on the magnitude order of the correlation coefficients is released, the conclusions from the tests are not changed: $\mathrm{KS}_{3}$ appears as the most balanced index. The number of models with validated (unconstrained) tests increases for most of the $\mathrm{KS}$ indices (apart from $\mathrm{KS}_{8}$ and $\mathrm{KS}_{9}$, for which it remains equal to zero), yet the $\mathrm{KS}_{3}$ index still has the highest number, with 99 models. When unconstrained, the rank correlation tests are validated for a majority of models with four other indices, including $\mathrm{KS}_{1}$ and $\mathrm{KS}_{2}$, with 95 and 52 models, respectively.

\section{Selection of the most promising $K S$ index}

Based on the classification tree (Fig. 1), we could confirm (or not) the keystone groups identified with each of the $12 \mathrm{KS}$ indices, for each of the 101 models (Table 3 ). The number of models with a validated keystone group (i.e., belonging to the keystone categories of the classification tree) ranges from 15 to 59 , over all $\mathrm{KS}$ indices. The $\mathrm{KS}_{3}$ index shows one of the highest scores (with 48 models), whereas the $\mathrm{KS}_{1}$ and $\mathrm{KS}_{2}$ indices show lower scores (with 15 and 34 models, respectively).

Then, by comparing the results from the rank correlation tests and the classification tree, we could allocate alternative statuses to each of the 101 models, for each of the $12 \mathrm{KS}$ indices (Fig. 2). Since 33 models were allocated a no keystone status (no functional groups in these models were categorized as keystone with the classification tree), the majority was reduced to 35 models to determine the overall status of each $\mathrm{KS}$ index. The outcomes from the status allocation corroborate the selection of the $\mathrm{KS}_{3}$ index as the most promising one. Indeed, $\mathrm{KS}_{3}$ is the only index associated with a true positive overall status (with 40 true positive models), meaning that results from the tests (step 1) and the classification tree (step 2) are both positive for a majority of models (Table 3). Two indices, $\mathrm{KS}_{5}$ and $\mathrm{KS}_{9}$, are allocated a true negative overall status (with 46 and 53 true negative models, respectively), traducing negative conclusions from both steps 1 and 2. For three of the $\mathrm{KS}$ indices $\left(\mathrm{KS}_{1}, \mathrm{KS}_{2}\right.$, and $\left.\mathrm{KS}_{6}\right)$, none of the statuses are associated with the majority of models, so that no overall status is determined for these indices. Nonetheless, we note that the number of true negative (false negative, respectively) models is close to the majority for $\mathrm{KS}_{1}\left(\mathrm{KS}_{2}\right.$, respectively; with 32 models in each case). The remaining KS indices are allocated a false negative overall status, indicating a negative result from the tests while the result from the classification tree is positive.

\section{Identification of potential keystone groups with the selected $K S$ index and the classification tree}

The selected $\mathrm{KS}_{3}$ index was applied to the 101 selected Ecopath models, so that the results from the whole analysis could be analyzed in terms of species (or groups). We compared, across the 101 selected models, the keystone groups most frequently identified with the $\mathrm{KS}_{3}$ index (i.e., with the highest value of keystoneness) and with the classification tree (i.e., belonging to the high or low TL keystone categories).

Groups are labeled using 12 generic group names, to standardize their heterogeneous original designations (Fig. 5a, b). Fish groups are separated into four groups: Elasmobranchii (including groups of sharks and rays), Gadiformes (cod and hake groups), Scombroidei (tunas, billfishes, and barracudas groups), and fishes (all the other groups of fishes). We note that the fishes group 


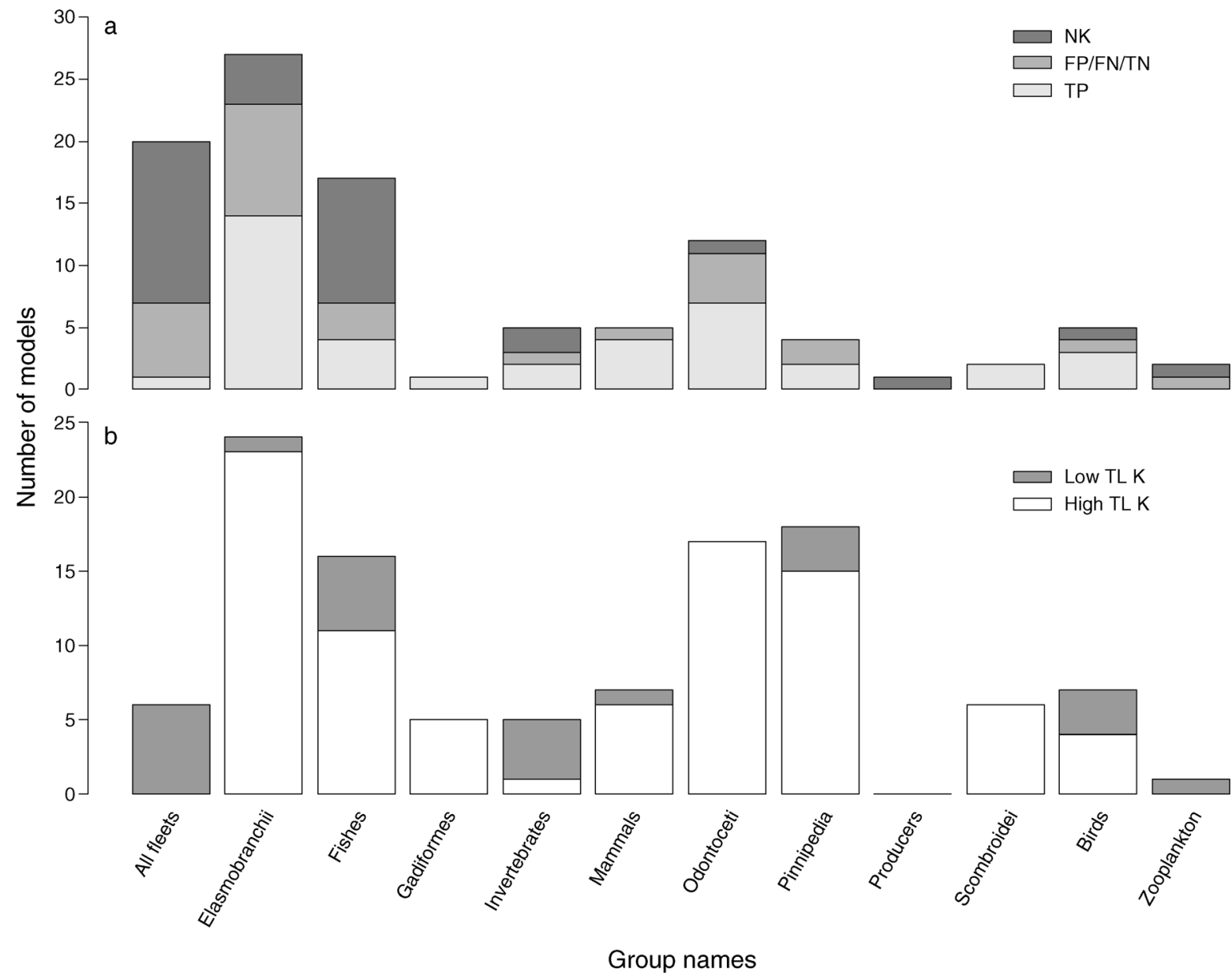

FIG. 5. Bar plots of the groups identified as keystone with (a) the selected $\mathrm{KS}_{3}$ index (see Table 1), and (b) the classification tree. Values are expressed in number of models, over the 101 selected Ecopath models. Based on their original names in each model, the identified keystone groups are aggregated into 12 broader groups: all fleets, Elasmobranchii, fishes, Gadiformes, invertebrates, mammals, Odontoceti, Pinnipedia, producers, Scombroidei, birds, and zooplankton. With the $\mathrm{KS}_{3}$ index, the identified keystone groups may be discriminated based on the status of the model: true positive (TP), false positive, false negative, or true negative (FP/ FN/TN), and no keystone (NK). With the classification tree, the identified keystone groups may be classified as either high TL keystone (high TL K) or low TL keystone (low TL K).

corresponds to a relatively wide range of species, aggregating groups of both large pelagic and small demersal species, because they all have low occurrences as identified keystone groups. Mammal groups are separated between Odontoceti (comprising groups of dolphins and orcas, as well as unspecified toothed whales), Pinnipedia (seals, sea lions, and walruses groups), and mammals (baleen whales groups, and unspecified groups of cetaceans and mammals). The other groups separate seabirds (all groups of birds) from invertebrates (comprising crustaceans, cephalopods, and unspecified invertebrates). The zooplankton, producers, and all-fleets groups are unchanged from their original designations.

Overall, the groups identified as keystone species with the highest occurrences across models correspond to cartilaginous fishes and toothed whales (Fig.
$5 \mathrm{a}, \mathrm{b})$.The most frequently identified groups with the $\mathrm{KS}_{3}$ index, across the 101 models, are Elasmobranchii, all fleets, fishes, and Odontoceti (Fig. 5a). In comparison, the most frequently identified groups with the classification tree, across the 101 models, are Elasmobranchii, Pinnipedia, Odontoceti, and fishes (Fig. 5b). With the classification tree, the identified keystone groups may be separated by their trophic level (Fig. $5 b)$. Thus, Odontoceti scores higher than Pinnipedia when considering high TL keystone only. Besides, all fleets are low TL keystone, as well as a substantial proportion of the seabirds and fishes. The keystone groups identified with the $\mathrm{KS}_{3}$ index may be separated based on the status of the models (Fig. 5a). Thus, the most frequently identified groups associated with a true positive status are Elasmobranchii and Odontoceti. In contrast, the most frequently identified groups associ- 


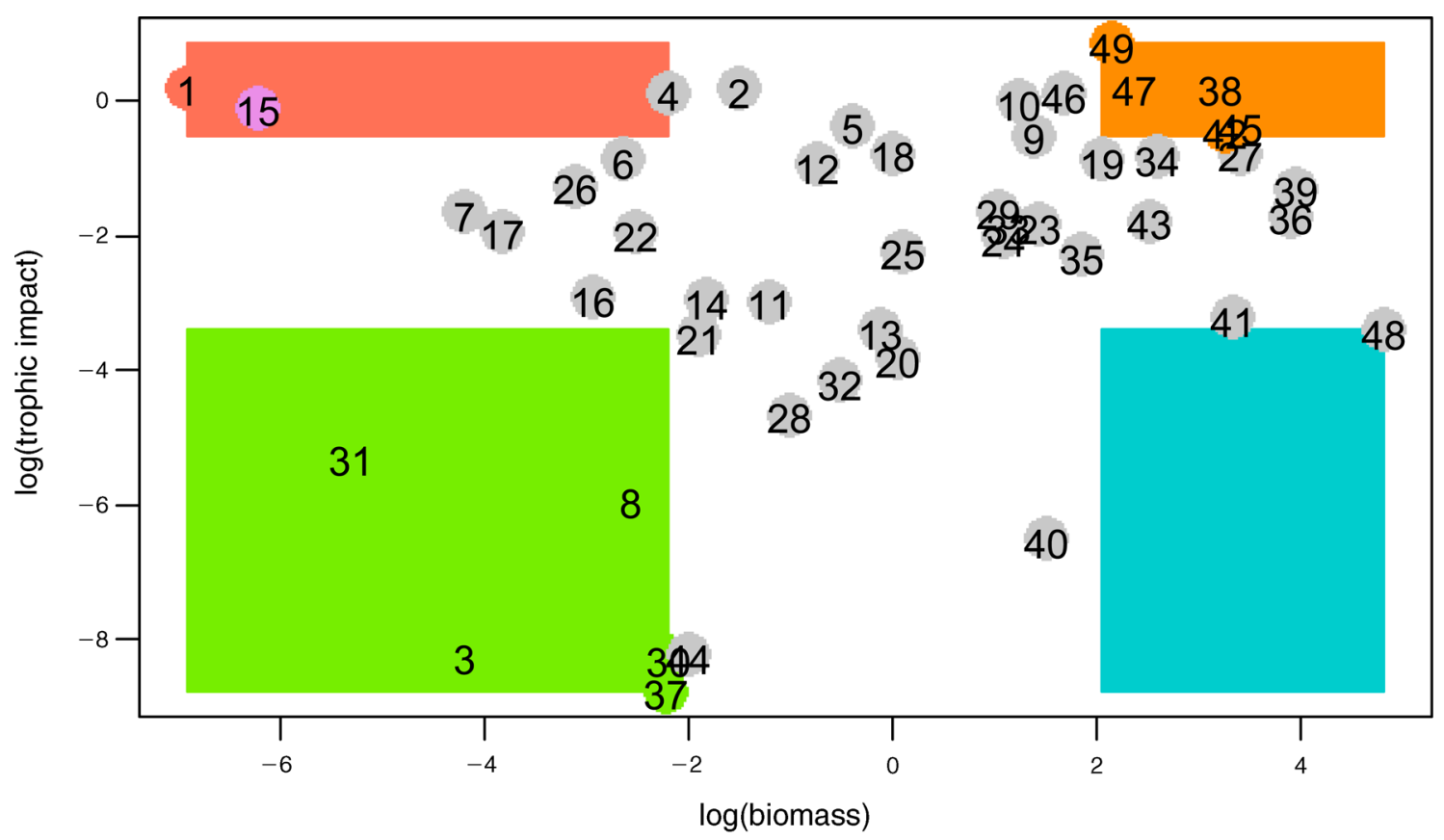

\section{Group names}

\begin{tabular}{|c|c|c|}
\hline 1) TransientOrca & 14) Spinydogfish & 27) DeepEpibent \\
\hline 2) SalmonSharks & 15) AvianPredators & 28) Capelin \\
\hline 3) ResidentOrca & 16) Octopods & 29) AdultHerring \\
\hline 4) SleeperSharks & 17) Seabirds & 30) Pollock0 \\
\hline 5) Halibut & 18) DeepDemersals & 31) InverteaterBird \\
\hline 6) Pinnipeds & 19) Pollock1plus & 32) Sandlance \\
\hline 7) Porpoise & 20) Rockfish & 33) ShalLgEpibent \\
\hline 8) Lingcod & 21) BaleenWhales & 34) JuvHerring \\
\hline 9) AdultAtooth & 22) SalmonFry0to12 & 35) Jellies \\
\hline 10) AdultSalmon & 23) NearshoreDemersal & 36) DeepSmInfauna \\
\hline 11) PacificCod & 24) Squid & 37) NearOmniZoo \\
\hline 12) Sablefish & 25) Eulachon & 38) OmniZooplankton \\
\hline 13) JuvAtooth & 26) Seaotters & 39) ShalSmInfauna \\
\hline
\end{tabular}

40) Meiofauna

41) DeepLglnfauna

42) ShalSmEpibent

43) ShalLglnfauna

44) NearHerbiZoo

45) HerbiZooplankton

46) NearPhytoplankton

47) OffshorePhyto

48) MacroalgaeGras

49) AllFleets

FIG. 6. Application of the classification tree (see Fig. 1) to the Prince William Sound (1994-1996) food web (Okey and Pauly 1999). The scatterplot shows the log-transformed biomass $\left(B_{i}\right)$ on the $x$-axis, and the log-transformed trophic impact (in squared values; $\varepsilon_{i}^{2}$ ) on the $y$-axis. Each point is a functional group in the model, identified with a group number and a group name (indicated in the legend). Groups belonging to each category are displayed in the same color as the corresponding category box: keystone groups in light red (upper-left box), high-impact-high-biomass groups in orange (upper-right box), low-impact-low-biomass groups in green (lower-left box), and low-impact-high-biomass groups in blue (lower-right box). Keystone groups are subdivided into two categories: low TL keystone in pink, and high TL keystone in light red. The all-fleets group, for which $B_{i}$ was approximated with the total catch $\left(Y_{\text {tot }}\right)$, corresponds to the aggregation of all the fishing fleets defined in the model.

ated with a no keystone status are all fleets and fishes. Finally, the high TL keystone groups, such as Scombroidei or Gadiformes, correspond to a true positive status. See Appendix C: Table $\mathrm{C} 4$ for the detailed results obtained with the selected $\mathrm{KS}_{3}$ index, for each model.

\section{Case study of the Prince William Sound (1994-1996) food web}

With the selected $\mathrm{KS}_{3}$ index, the Ecopath model of the Prince William Sound (1994-1996) shows positive results from the rank correlation tests. Also, the same groups are identified as potential keystone species, both with the classification tree (Fig. 6) and the selected $\mathrm{KS}_{3}$ index (Fig. 7a), in the Prince William Sound (19941996) food web. Transient orcas (group 1) are classified as high TL keystone and have the highest value of keystoneness with the $\mathrm{KS}_{3}$ index. Avian predators (group 15, mainly representing bald eagles) are categorized as low TL keystone and have the second-highest keystoneness value. Thus, the status of the selected $\mathrm{KS}_{3}$ index applied to the case study model is true positive. In contrast, with the $\mathrm{KS}_{1}$ and $\mathrm{KS}_{2}$ indices directly adapted from the literature, results from the classification tree are 
in disagreement with results from the rank correlation tests. More precisely, the groups having the highest values of keystoneness with the $\mathrm{KS}_{1}$ index belong to the high-impact-high-biomass category (Fig. 7b). With the $\mathrm{KS}_{2}$ index, although transient orcas and avian predators have the two highest keystoneness values, the correlation tests were not validated, seeing that the groups classified as low-impact-low-biomass have high keystoneness (Fig. 7c).

\section{DisCUSSION}

\section{A balanced index of keystoneness for marine food webs}

In this study, we derived a functional index estimating species keystoneness from a meta-analysis on a selection of 101 Ecopath models. The selection of models was representative of the variety of marine ecosystems worldwide. Also, most models were of good quality in terms of data. The Ecopath-based approach enabled us to use trophic impact and biomass as measurable species traits, and to propose ecosystem-specific thresholds of minimum trophic impact and maximum biomass for a species to be keystone. In each modeled food web, species were ranked according to their keystoneness estimates, so that the potential keystone species could be quantitatively identified. The new index of keystoneness proposed in our study (the $\mathrm{KS}_{3}$ index) was obtained by multiplying the $\mathrm{IC}_{\mathrm{L}}$ impact component (adapted from Libralato et al. 2006) by the $\mathrm{BC}_{0}$ biomass component (based on descending ranking, so that high biomass corresponds to low $\mathrm{BC}$ ). The usage of ranking in the biomass component enabled us to prevent "inflating uncertainty and errors in the index because measures for rare species are divided by small numbers" (Cottee-Jones and Whittaker 2012). The $\mathrm{KS}_{3}$ index was selected by confronting the results from two statistical methods: (1) Spearman's rank correlation tests (step 1) and (2) a classification tree (step 2). The selected index corresponded to the KS index with the highest number of models for which results from both steps 1 and 2 were positive.

The standardized Ecopath approach allowed for a comparison of the keystone groups identified across models. The generic groups of species with the highest occurrences across models were cartilaginous fishes and toothed whales, over all the 101 selected models. These species corresponded to the definition of keystone predator applied in this study. As for the case study model, the identification of a toothed whales species (transient orcas, see Plate 1) as a potential keystone group was consistent with empirical knowledge of the modeled ecosystem. Although sea otters are known as an historical example of keystone species in kelp forest ecosystems (Estes and Palmisano 1974), transient orcas were identified as keystone species in the Ecopath model of the Prince William Sound (1994-1996). Alaskan transient orcas were observed to be partially feeding on sea otters, which were mainly feeding on clams but rarely on sea urchins (Estes et al. 1998, Okey and Pauly 1999). Thus, the keystoneness of sea otters was reduced in the Prince William Sound food web, due to both the predation pressure from transient orcas (Estes et al. 1998), and the low abundance of grazers such as sea urchins (Paine 1980).

In this study, we established that the selected index $\left(\mathrm{KS}_{3}\right)$ seemed to be more balanced than the ones previously proposed in the literature and implemented in EwE $\left(\mathrm{KS}_{1}\right.$ and $\left.\mathrm{KS}_{2}\right)$. Both the $\mathrm{KS}_{1}$ and $\mathrm{KS}_{2}$ indices were applied to several modeled food webs, representing various types of marine ecosystems (e.g., Libralato et al. 2006, Coll and Libralato 2012, Coll et al. 2013). As for the six models selected in this study to which the latter indices were applied, the results from the $\mathrm{KS}_{1}$ index were not convincing for four of the models (Coll et al. 2007, Tsagarakis et al. 2010, Valls et al. 2012, Tecchio et al. 2013), and inconsistent results were obtained when both $\mathrm{KS}_{1}$ and $\mathrm{KS}_{2}$ indices were used. In this study, we confirmed that both $\mathrm{KS}_{1}$ and $\mathrm{KS}_{2}$ indices fail at attributing high keystoneness to groups having both low biomass and high trophic impact. The $\mathrm{KS}_{1}$ index frequently attributed high keystoneness to functional groups with high biomass, provided their trophic impact was high. Such groups should instead correspond to abundant species (Coll and Libralato 2012). In contrast, the $\mathrm{KS}_{2}$ index often gave high values for functional groups with low biomass, even though these groups had low trophic impact. Such groups should instead be categorized as rare species (Libralato et al. 2006, Coll et al. 2013). The $\mathrm{KS}_{3}$ index proposed in this study was demonstrated to have more balanced contributions between its trophic impact and biomass components in its estimation of species keystoneness. Therefore, the new index may be used to identify keystone species in marine food webs, without overrepresenting abundant or rare species.

\section{Methodological considerations on the derived functional $K S$ index}

The MTI analysis, like the Ecopath model, only gives a snapshot of the trophic web at one point in time, and should not be used for drawing conclusions on the consequences of changes in biomass over time. For instance, a decrease in the biomass of a predator might lead to an increase in the biomass of its prey in the short term. In the longer term, it might also result in higher biomasses of other predators, or changes in the predator's diet facing reduced prey abundance, but these cumulative effects cannot be predicted from the MTI analysis (Christensen and Walters 2004). However, the (positive or negative) $m_{i j}$ corresponds, for each pair of groups $(i, j)$ in the modeled food web, to the relative change (increase or decrease) in the biomass of the impacted group $j$, caused by a slight increase in biomass of the impacting groups $i$ (Libralato et al. 2006).

The main criticism about Ecopath-based approaches, especially when looking at keystone species, deals with the species aggregation into functional groups. Aggregating species is required to obtain smaller, simpler, and 

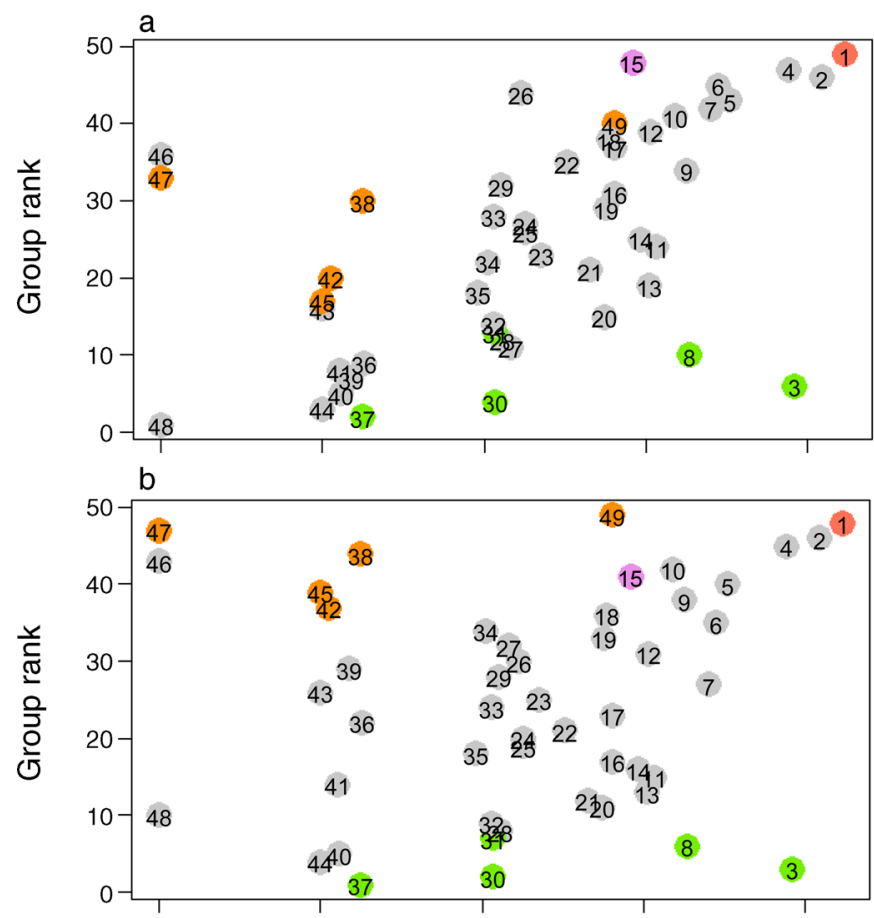

1) TransientOrca
2) SalmonSharks
3) ResidentOrca
4) SleeperSharks
5) Halibut
6) Pinnipeds
7) Porpoise
8) Lingcod
9) AdultAtooth
10) AdultSalmon
11) PacificCod
12) Sablefish
13) JuvAtooth
14) Spinydogfish
15) AvianPredators
16) Octopods
17) Seabirds
18) DeepDemersals
19) Pollock1plus
20) Rockfish
21) BaleenWhales
22) SalmonFryOto12
23) NearshoreDemersal
24) Squid
25) Eulachon

26) Seaotters

27) DeepEpibent

28) Capelin

29) AdultHerring

30) Pollock0

31) InverteaterBird

32) Sandlance

33) ShallgEpibent

34) JuvHerring

35) Jellies

36) DeepSmInfauna

37) NearOmniZoo

38) OmniZooplankton

39) ShalSmlnfauna

40) Meiofauna

41) DeepLgInfauna

42) ShalSmEpibent

43) ShalLgInfauna

44) NearHerbiZoo

45) HerbiZooplankton

46) NearPhytoplankton

47) OffshorePhyto

48) MacroalgaeGras

49) AllFleets

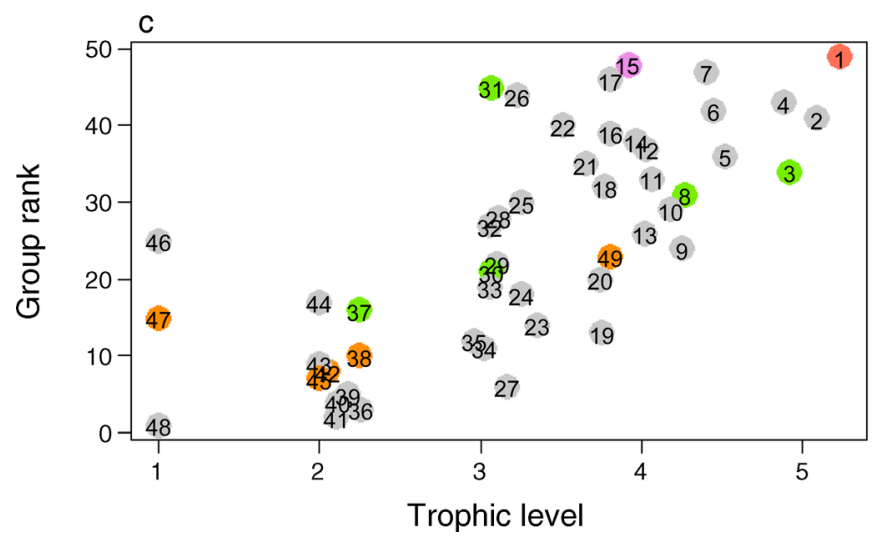

FIG. 7. Application of the (a) $\mathrm{KS}_{3}\left(\mathrm{IC}_{\mathrm{L}} \times \mathrm{BC}_{0}\right)$, (b) $\mathrm{KS}_{1}\left(\mathrm{IC}_{\mathrm{L}} \times \mathrm{BC}_{\mathrm{L}}\right)$, and (c) $\mathrm{KS}_{2}\left(\mathrm{IC}_{\mathrm{L}} \times \mathrm{BC}_{\mathrm{P}}\right)$ indices (see Table 1) to the Prince William Sound (1994-1996) food web (Okey and Pauly 1999). Each scatterplot shows the rank of the functional group, based on its index of keystoneness in ascending order (keystone species have high ranks) on the $x$-axis, and the trophic level ( $\left(T L_{i}\right)$ of the functional group on the $y$-axis. Each dot is a functional group in the model, identified with a group number and a group name (indicated in the legend). Groups are displayed in the color of the category they were associated with on the classification tree (see Fig. 6).

easier-to-analyze food webs. A few methods of aggregation are commonly used, yet there are no systematic aggregation rules, which potentially introduce taxonomic bias (Jordán 2009). Other than mass-balance foodweb models, alternative methods to identify ecologically important species, such as keystone species, are based on ecological network analyses (ENA). ENA-based approaches are used to derive quantitative structural indices describing species position in complex networks of interspecific interactions (e.g., Estrada 2007, Jordán 2009, Jordán et al. 2009). ENA methods consist of topological studies applied in ecology to characterize the positional importance of species in communities, by considering the number of trophic links between species, but not necessarily the strength of the links (Jordán 2009). Such methods were first applied to binary networks only (e.g., Jordán et al. 2003), and then adapted to weighted networks (e.g., Scotti et al. 2007, Jordán et al. 2008), since weighted structural indices were demonstrated to best correlate with functional indices from EwE-based methods (Jordán et al. 2008). As with food-web models, ecological networks are aggregated to some extent, seeing that all species are directly or indirectly interconnected in the food web (Jordán 2009). Besides, ENA studies are based on the Lotka-Volterra assumption of uniform and random 


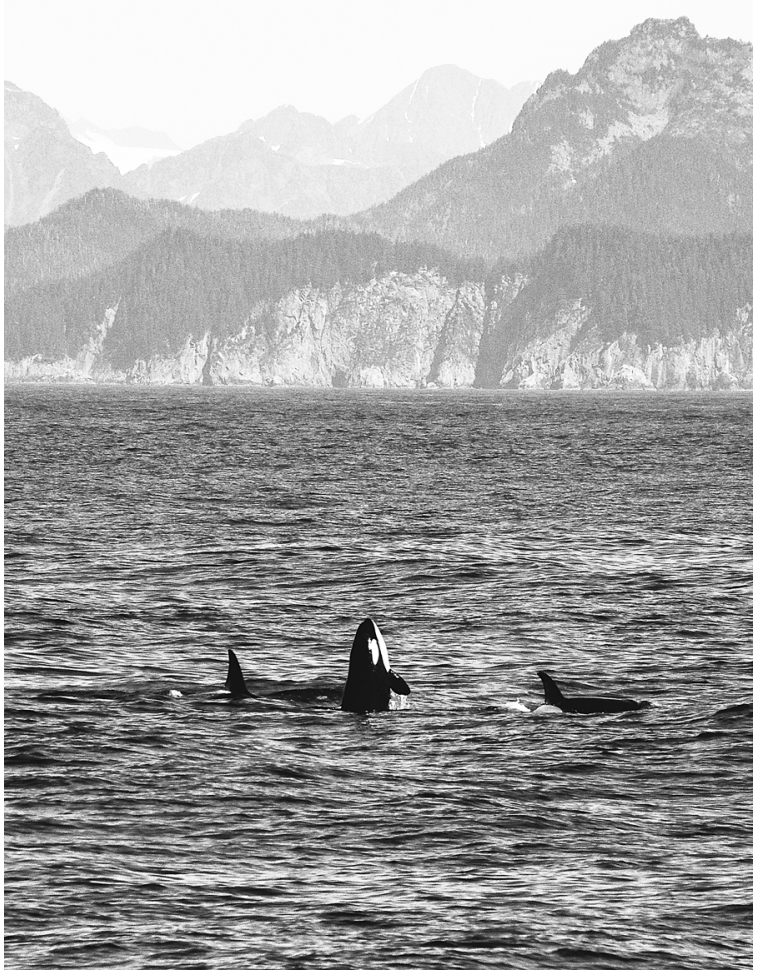

Plate 1. Orcas in Alaska. Photo credit: Arnaud Bethier 2013.

distribution of interactions between species (e.g., Christianou and Ebenman 2005). Yet, the latter assumption was proven to be unrealistic, compared to the foraging arena theory implemented in EwE models (Walters and Martell 2004, Walters and Christensen 2007, Ahrens et al. 2012). Finally, community structure and dynamics were shown to be correlated in EwE studies (Libralato et al. 2006). Likewise, another challenge for ENA-based approaches is to understand species importance, not only in terms of network position, but also regarding network dynamics (Jordán 2009).

\section{Perspectives for future directions in keystoneness analyses}

The major challenge in the quest for keystone species is the estimation of the time and space required to assess potential keystone effects (Paine 1995, Power and Mills 1995). Thus, the temporal and spatial scales considered are determinant to the identification of keystone species. Although static patterns differ from dynamic processes (Paine 1980, Arponen 2012), it was verified that the keystoneness of species may be inferred without performing time-dynamic analyses (Libralato et al. 2006). Thus, in this study, we chose to compare Ecopath models of past and present ecosystem states, rather than using Ecosim simulations. Such an approach was previously applied to a selection of models representing upwelling ecosystems at different time periods (Libralato et al. 2006), or used to analyze the effects of the establishment of an MPA (Coll et al. 2009, Eddy et al. 2014). Here, we preferentially selected models representing the same ecosystem at different temporal periods (sibling models) or spatial scales (overlapping models), in order to integrate temporal and spatial variability. We ended up with very few (only two) overlapping models, so that we could not analyze the influence of spatial scale. In contrast, our selection of Ecopath models comprised a large number of sibling models, which were used to explore context-dependency issues a little further. We used the selected sibling models to compare the changes in identified keystone groups over time in the same ecosystem. However, no consistent pattern could be identified across our selection of sibling models. A more in-depth analysis would be required to fully understand the interacting factors affecting species keystoneness over time.

Human-induced variability may be a factor of potential influence on species keystoneness. Anthropogenic impacts may lead to the loss of keystone species (first becoming rare, and then disappearing) and the community architecture they maintained, leaving an altered ecosystem where species are less likely to play keystone roles (Paine 1995). On the contrary, Power et al. (1996) argued that loss of species diversity may lead to the remaining species taking on keystone roles. Using the $\mathrm{KS}_{1}$ and $\mathrm{KS}_{2}$ indices, several authors demonstrated that ecosystems highly affected by fishing impact had less prevalence of keystone species, whose role was modified with increased fishing pressure. As an example, in the Mediterranean Sea, the proportion of keystone species in fully exploited ecosystems was shown to be less than in protected (or slightly exploited) ecosystems, while the proportion of abundant species was comparable across ecosystems (Coll and Libralato 2012). A similar pattern was observed globally, in a study considering coastal ecosystems from all over the world ocean (Heymans et al. 2012). Keystone species in nonexploited marine ecosystems may become rare when over-exploitation occurs, such as cetaceans in the Mediterranean Sea (Coll et al. 2009), or groupers in the Galapagos (Okey et al. 2004). Similarly, the keystone species status of lobsters in New Zealand was shown to be impacted by fisheries (Eddy et al. 2014). Consequently, human activities could result in large-scale removals of potential keystone species, without any record of the ecosystem state before the uncontrolled removals (Power et al. 1996). Human-induced climate change may be determinant to the keystone role of species as well (Harley 2011). Through the same mechanisms as in natural variability, human-induced variability may lead to competitive balance shifts and predator removals, and thus alter species interactions (Poloczanska et al. 2008). 
The fishing fleets defined in the selected Ecopath models were included as human predators in our analysis, so as to consider potentially significant anthropogenic (fishing) impacts on keystone species. The all-fleets group appeared as a frequently identified keystone group with the selected index (Fig. 5a), which could suggest a significant effect of fishing on keystone species in the corresponding modeled food webs. However, the keystoneness of the all-fleets group was not confirmed with the classification tree, since most corresponding models were allocated a no keystone status (Fig. 5a). We observed that the overall match and overall status of the different $\mathrm{KS}$ indices were not modified by the inclusion of fishing fleets in the calculation of the mixed-trophic impacts. Nonetheless, the sensitivity of the identified keystone group to the addition of the all-fleets group in the analysis varied among the different KS indices. Ideally, an index of keystoneness would consider context-dependency aspects and identify keystone species differently depending on the status of the ecosystem. Alternatively, a suite of complementary indices, each best adapted to a specific level of exploitation, could be developed and applied according to the situation. So, further analyses could explore the sensitivity of the proposed $\mathrm{KS}$ index to context dependency, by comparing the changes in identified keystone species with the changes in fishing pressure in the modeled food web. In the literature, sensitivity analyses on matrix models representing ecological succession were notably used to quantify the relative importance of species interactions to community composition and proposed as a method to identify keystone species (Tanner et al. 1994). In addition, we could investigate the robustness of the proposed $\mathrm{KS}$ index to uncertainty and possible model construction errors. Structural indices for binary food webs, such as the mixed-trophic impact, were demonstrated to be robust to uncertainty (Fedor and Vasas 2009), so that the equivalent functional indices for weighted food webs, used in our approach, may be assumed to be robust as well. Yet, the development of a measure of robustness for functional indices of keystoneness, similar to the one applied to structural indices, would constitute interesting questions for future studies.

\section{Toward an index of keystoneness applicable to biodiversity conservation}

In this study, we developed an operational methodology, directly applicable to marine ecosystems, and possibly adaptable to other types of systems (freshwater or terrestrial). Food-web dynamics and keystone species may respond differently, depending on the type of ecosystem (Bond 2001, Link 2002). The response to species introduction or removal is known to be generally slow in natural ecosystems, but the time scale is thought to be shorter in aquatic ecosystems, especially lakes, than in terrestrial ones (Bond 1994, 2001, Power et al. 1996). Marine food webs differ from other types of food webs by their higher connectivity, due to large ontogenetic changes in size and diet of marine species, which are opportunistic feeders in an open foraging range (Link 2002). Therefore, the detection of keystone mechanisms might be easier in freshwater or terrestrial food webs.

Conserving biodiversity is often a compromise between protecting species, areas, or processes (Simberloff 1998). Among the critical ecological processes maintaining whole communities, some are driven by critical species, which thus have to be identified and used in the "conservation biologist's toolbox" (Power et al. 1996). Critical species play an important ecological function, performed by few other species in the ecosystem, such as keystone species that maintain the food-web structure of their community (Perry 2010). Thus, identifying and protecting critical species may be the only long-term solution to preserve a "working ecosystem rather than a collection of charismatic species" (Jordán 2009, Perry 2010). In this study, we focused on the keystone species category, yet other categories of critical species may be identified with the classification tree. Indeed, species belonging to the high-impact-high-biomass category may correspond to critical food resources in the food web. On the contrary, the low-impact-low-biomass category may include some rare species, which could be potentially endangered or ecologically extinct. Lastly, the fourth category of low-impact-high-biomass species may represent critical habitat species in the ecosystem. In practice, analyzing functional roles in species assemblages is determinant to setting conservation priorities and defining restoration programs (McClanahan 2000, Clemente et al. 2010). The identification of functionally important species, such as keystone species, not only helps in developing effective conservation strategies for species-level prioritization, but also a better understanding of ecosystem functioning and processes (Jordán 2009, Clemente et al. 2010). Moving toward a fully operational and widely applicable index of species keystoneness would thus constitute one step further in biodiversity conservation.

\section{ACKNOWLEDGMENTS}

The authors thank all modelers who made their Ecopath models available for reuse in this study. The authors also thank two anonymous referees for their very valuable comments on an earlier version of the manuscript. A. Valls acknowledges support from the Nereus Program, a scientific cooperation between the Nippon Foundation and the University of British Columbia with six additional partners. M. Coll was supported by a Marie Curie CIG grant to BIOWEB and the Spanish Research Program Ramon y Cajal. V. Christensen acknowledges support from the Natural Sciences and Engineering Research Council of Canada.

\section{Literature Cited}

Ahrens, R. N., C. J. Walters, and V. Christensen. 2012. Foraging arena theory. Fish and Fisheries 13:41-59.

Arponen, A. 2012. Prioritizing species for conservation planning. Biodiversity and Conservation 21:875-893.

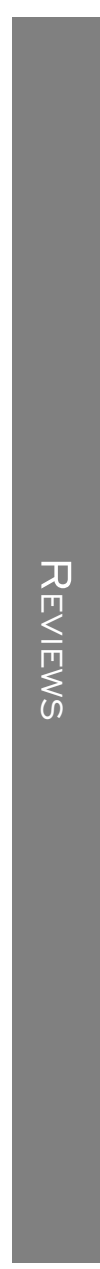


Aydin, K. Y., V. Lapko, V. Radchenko, and P. Livingston 2002. A comparison of the eastern Bering and western Bering Sea shelf and slope ecosystems through the use of massbalance food web models. Technical memo NMFS-AFSC130. US Department of Commerce, National Oceanic and Atmospheric Administration, National Marine Fisheries Service, Alaska Fisheries Science Center, Seattle, Washington, USA.

Barua, M. 2011. Mobilizing metaphors: the popular use of keystone, flagship and umbrella species concepts. Biodiversity and Conservation 20:1427-1440.

Berg, S., M. Christianou, T. Jonsson, and B. Ebenman. 2011. Using sensitivity analysis to identify keystone species and keystone links in size-based food webs. Oikos 120:510-519.

Bond, W. 1994. Keystone species. Pages 237-253 in E. D. Schulze and H. A. Mooney, editors. Biodiversity and ecosystem function. Springer, Berlin, Germany.

Bond, W. 2001. Keystone species - hunting the snark? Science 292:63-64.

Christensen, V., and D. Pauly. 1992. Ecopath II-a software for balancing steady-state ecosystem models and calculating network characteristics. Ecological Modelling 61:169-185.

Christensen, V., C. Piroddi, M. Coll, J. Steenbeek, J Buszowski, and P. Daniel. 2011. Fish biomass in the world ocean: a century of decline. Fisheries Centre Working Paper Series 6:20.

Christensen, V., and C. Walters. 2004. Ecopath with Ecosim: methods, capabilities and limitations. Ecological Modelling 172:109-139.

Christensen, V., C. Walters, D. Pauly, and R. Forrest. 2008. Ecopath with Ecosim version 6 user guide. Lenfest Ocean Futures Project, University of British Columbia, Vancouver, British Columbia, Canada.

Christianou, M., and B. Ebenman. 2005. Keystone species and vulnerable species in ecological communities: strong or weak interactors? Journal of Theoretical Biology 235:95-103.

Clemente, S., J. C. Hernández, A. Rodríguez, and A. Brito. 2010. Identifying keystone predators and the importance of preserving functional diversity in sublittoral rocky-bottom areas. Marine Ecology Progress Series 413:55-67.

Coleman, J. S. M. 2010. Spearman rank order correlation. Pages 1405-1408 in N. J. Salkind, editor. Encyclopedia of research design. SAGE Publications, Thousand Oaks, California, USA.

Coll, M., A. Bundy, and L. J. Shannon. 2008. Ecosystem modelling using the Ecopath with Ecosim approach. Pages 225-291 in B. Megrey and E. Moksness, editors. Computers in fisheries research. Second edition. Springer, Berlin, Germany.

Coll, M., and S. Libralato. 2012. Contributions of food web modelling to the ecosystem approach to marine resource management in the Mediterranean Sea. Fish and Fisheries 13:60-88.

Coll, M., J. Navarro, and I. Palomera. 2013. Ecological role, fishing impact, and management options for the recovery of a Mediterranean endemic skate by means of food web models. Biological Conservation 157:108-120.

Coll, M., A. Santojanni, I. Palomera, and E. Arneri. 2009. Food-web changes in the Adriatic Sea over the last three decades. Marine Ecology Progress Series 381:17-37.

Coll, M., A. Santojanni, I. Palomera, S. Tudela, and E. Arneri. 2007. An ecological model of the northern and central Adriatic Sea: analysis of ecosystem structure and fishing impacts. Journal of Marine Systems 67:119-154.

Colléter, M., A. Valls, J. Guitton, L. Morissette, F. ArreguínSánchez, V. Christensen, D. Gascuel, and D. Pauly. 2013. EcoBase: a repository solution to gather and communicate information from EwE models. Fisheries Centre, Vancouver, British Columbia, Canada.

Cottee-Jones, H. E. W., and R. J. Whittaker. 2012. The keystone species concept: a critical appraisal. Frontiers of Biogeography 4:117-127.
Davic, R. D. 2003. Linking keystone species and functional groups: a new operational definition of the keystone species concept. Conservation Ecology 7:r11.

De Leo, G. A., and S. Levin. 1997. The multifaceted aspects of ecosystem integrity. Conservation Ecology 1:3.

Ebenman, B., and T. Jonsson. 2005. Using community viability analysis to identify fragile systems and keystone species. Trends in Ecology and Evolution 20:568-575.

Eddy, T. D., T. J. Pitcher, A. B. MacDiarmid, T. T. Byfield, J. C. Tam, T. T. Jones, J. J. Bell, and J. Gardner. 2014. Lobsters as keystone: only in unfished ecosystems? Ecological Modelling 275:48-72.

Estes, J. A., and J. F. Palmisano. 1974. Sea otters: their role in structuring nearshore communities. Science 185:1058-1060.

Estes, J. A., M. T. Tinker, T. M. Williams, and D. F. Doak. 1998. Killer whale predation on sea otters linking oceanic and nearshore ecosystems. Science 282:473-476.

Estrada, E. 2007. Characterization of topological keystone species: local, global and "meso-scale" centralities in food webs. Ecological Complexity 4:48-57.

Fedor, A., and V. Vasas. 2009. The robustness of keystone indices in food webs. Journal of Theoretical Biology 260:372378.

Harley, C. D. 2011. Climate change, keystone predation, and biodiversity loss. Science 334:1124-1127.

Heymans, J. J., M. Coll, S. Libralato, and V. Christensen. 2012. Ecopath theory, modeling, and application to coastal ecosystems. Pages 93-113 in E. Wolanski and D. McLusky, editors. Treatise on estuarine and coastal science. Academic Press, Waltham, Massachusetts, USA.

Hurlbert, S. 1997. Functional importance vs keystoneness: reformulating some questions in theoretical biocenology. Australian Journal of Ecology 22:369-382.

Jordán, F. 2009. Keystone species and food webs. Philosophical Transactions of the Royal Society B 364:1733-1741.

Jordán, F., Z. Benedek, and J. Podani. 2007. Quantifying positional importance in food webs: a comparison of centrality indices. Ecological Modelling 205:270-275.

Jordán, F., W. C. Liu, and Á. Mike. 2009. Trophic field overlap: a new approach to quantify keystone species. Ecological Modelling 220:2899-2907.

Jordán, F., W. C. Liu, and J. van Veen. 2003. Quantifying the importance of species and their interactions in a hostparasitoid community. Community Ecology 4:79-88.

Jordán, F., T. A. Okey, B. Bauer, and S. Libralato. 2008. Identifying important species: linking structure and function in ecological networks. Ecological Modelling 216:75-80.

Jordán, F., A. Takács-Sánta, and I. Molnár. 1999. A reliability theoretical quest for keystones. Oikos 453-462.

Kitchell, J. F., T. E. Essington, C. H. Boggs, D. E. Schindler, and C. J. Walters. 2002. The role of sharks and longline fisheries in a pelagic ecosystem of the central Pacific. Ecosystems 5:202-216.

Libralato, S., V. Christensen, and D. Pauly. 2006. A method for identifying keystone species in food web models. Ecological Modelling 195:153-171.

Link, J. 2002. Does food web theory work for marine ecosystems? Marine Ecology Progress Series 230:1-9.

McClanahan, T. 2000. Recovery of a coral reef keystone predator, Balistapus undulatus, in East African marine parks. Biological Conservation 94:191-198.

Menge, B. A., E. L. Berlow, C. A. Blanchette, S. A. Navarrete, and S. B. Yamada. 1994. The keystone species concept: variation in interaction strength in a rocky intertidal habitat. Ecological Monographs 64:249-286.

Mills, L. S., M. E. Soule, and D. F. Doak. 1993. The keystonespecies concept in ecology and conservation. BioScience 43:219-224.

Okey, T. A., S. Banks, A. F. Born, R. H. Bustamante, M. Calvopiña, G. J. Edgar, E. Espinoza, J. M. Fariña, L. E. Garske, and G. K. Reck. 2004. A trophic model of a 
Galápagos subtidal rocky reef for evaluating fisheries and conservation strategies. Ecological Modelling 172:383-401.

Okey, T. A., and D. Pauly. 1999. Trophic mass-balance model of Alaska's Prince William Sound ecosystem, for the postspill period 1994-1996. University of British Columbia, Vancouver, British Columbia, Canada.

Ortiz, M., L. Campos, F. Berrios, F. Rodriguez, B. Hermosillo, and J. González. 2013a. Network properties and keystoneness assessment in different intertidal communities dominated by two ecosystem engineer species (SE Pacific coast): a comparative analysis. Ecological Modelling 250:307-318.

Ortiz, M., R. Levins, L. Campos, F. Berrios, F. Campos, F. Jordán, B. Hermosillo, J. Gonzalez, and F. Rodriguez. $2013 b$. Identifying keystone trophic groups in benthic ecosystems: implications for fisheries management. Ecological Indicators 25:133-140.

Paine, R. T. 1966. Food web complexity and species diversity. American Naturalist 100:65-75.

Paine, R. T. 1969. A note on trophic complexity and community stability. The American Naturalist 103:91-93.

Paine, R. T. 1980. Food webs: linkage, interaction strength and community infrastructure. Journal of Animal Ecology 49:667-685.

Paine, R. T. 1992. Food-web analysis through field measurement of per capita interaction strength. Letters to Nature 355:73-75.

Paine, R. T. 1995. A conversation on refining the concept of keystone species. Conservation Biology 9:962-964.

Perry, N. 2010. The ecological importance of species and the Noah's Ark problem. Ecological Economics 69:478-485.

Poloczanska, E. S., S. J. Hawkins, A. J. Southward, and M. T. Burrows. 2008. Modeling the response of populations of competing species to climate change. Ecology 89:3138-3149.

Polovina, J. J. 1984. Model of a coral reef ecosystem. Coral Reefs 3:1-11.

Power, M. E., and L. S. Mills. 1995. The keystone cops meet in Hilo. Trends in Ecology and Evolution 10:182-184.

Power, M. E., D. Tilman, J. A. Estes, B. A. Menge, W. J. Bond, L. S. Mills, G. Daily, J. C. Castilla, J. Lubchenco, and R. T. Paine. 1996. Challenges in the quest for keystones. BioScience 46:609-620.

R Development Core Team. 2014. R: a language and environment for statistical computing. $\mathrm{R}$ Foundation for Statistical Computing, Vienna, Austria. www.r-project.org
Scotti, M., J. Podani, and F. Jordán. 2007. Weighting, scale dependence and indirect effects in ecological networks: a comparative study. Ecological Complexity 4:148-159.

Simberloff, D. 1998. Flagships, umbrellas, and keystones: is single-species management passé in the landscape era? Biological Conservation 83:247-257.

Stouffer, D. B., M. Sales-Pardo, M. I. Sirer, and J. Bascompte. 2012. Evolutionary conservation of species' roles in food webs. Science 335:1489-1492.

Tanner, J. E., T. P. Hughes, and J. H. Connell. 1994. Species coexistence, keystone species, and succession: a sensitivity analysis. Ecology 75:2204-2219.

Tecchio, S., M. Coll, V. Christensen, E. Ramírez-Llodra, and F. Sardà. 2013. Food web structure and vulnerability of a deepsea ecosystem in the NW Mediterranean Sea. Deep Sea Research Part I-Oceanographic Research Papers 75:1-15.

Torres-Alruiz, M. D., and D. J. Rodríguez. 2013. A topodynamical perspective to evaluate indirect interactions in trophic webs: new indexes. Ecological Modelling 250:363369.

Tsagarakis, K., M. Coll, M. Giannoulaki, S. Somarakis, C. Papaconstantinou, and A. Machias. 2010. Food-web traits of the North Aegean Sea ecosystem (Eastern Mediterranean) and comparison with other Mediterranean ecosystems. Estuarine, Coastal and Shelf Science 88:233-248.

Ulanowicz, R. E., and C. J. Puccia. 1990. Mixed trophic impacts in ecosystems. Coenoses 5:7-16.

Valls, A., D. Gascuel, S. Guénette, and P. Francour. 2012. Modeling trophic interactions to assess the effects of a marine protected area: case study in the NW Mediterranean Sea. Marine Ecology Progress Series 456:201.

Walters, C., and V. Christensen. 2007. Adding realism to foraging arena predictions of trophic flow rates in Ecosim ecosystem models: shared foraging arenas and bout feeding. Ecological Modelling 209:342-350.

Walters, C., V. Christensen, and D. Pauly. 1997. Structuring dynamic models of exploited ecosystems from trophic massbalance assessments. Reviews in Fish Biology and Fisheries $7: 139-172$.

Walters, C., D. Pauly, and V. Christensen. 1999. Ecospace: prediction of mesoscale spatial patterns in trophic relationships of exploited ecosystems, with emphasis on the impacts of Marine Protected Areas. Ecosystems 2:539-554.

Walters, C. J., and S. J. D. Martell. 2004. Fisheries ecology and management. Princeton University Press, Princeton, New Jersey, USA.

\section{Supplemental Material}

\section{Ecological Archives}

Appendices A-C and the Supplement are available online: http://dx.doi.org/10.1890/14-0306.1.sm 